This item was submitted to Loughborough's Research Repository by the author.

Items in Figshare are protected by copyright, with all rights reserved, unless otherwise indicated.

\title{
The effect of interface topography for Ultrasonic Consolidation of aluminium
}

\section{PLEASE CITE THE PUBLISHED VERSION}

http://dx.doi.org/10.1016/j.msea.2010.03.094

\section{PUBLISHER}

(c) Elsevier

VERSION

AM (Accepted Manuscript)

\section{LICENCE}

CC BY-NC-ND 4.0

\section{REPOSITORY RECORD}

Friel, Ross J., Kenneth E. Johnson, Phill M. Dickens, and Russell A. Harris. 2019. "The Effect of Interface Topography for Ultrasonic Consolidation of Aluminium”. figshare. https://hdl.handle.net/2134/7352. 
This item was submitted to Loughborough's Institutional Repository (https://dspace.lboro.ac.uk/) by the author and is made available under the following Creative Commons Licence conditions.

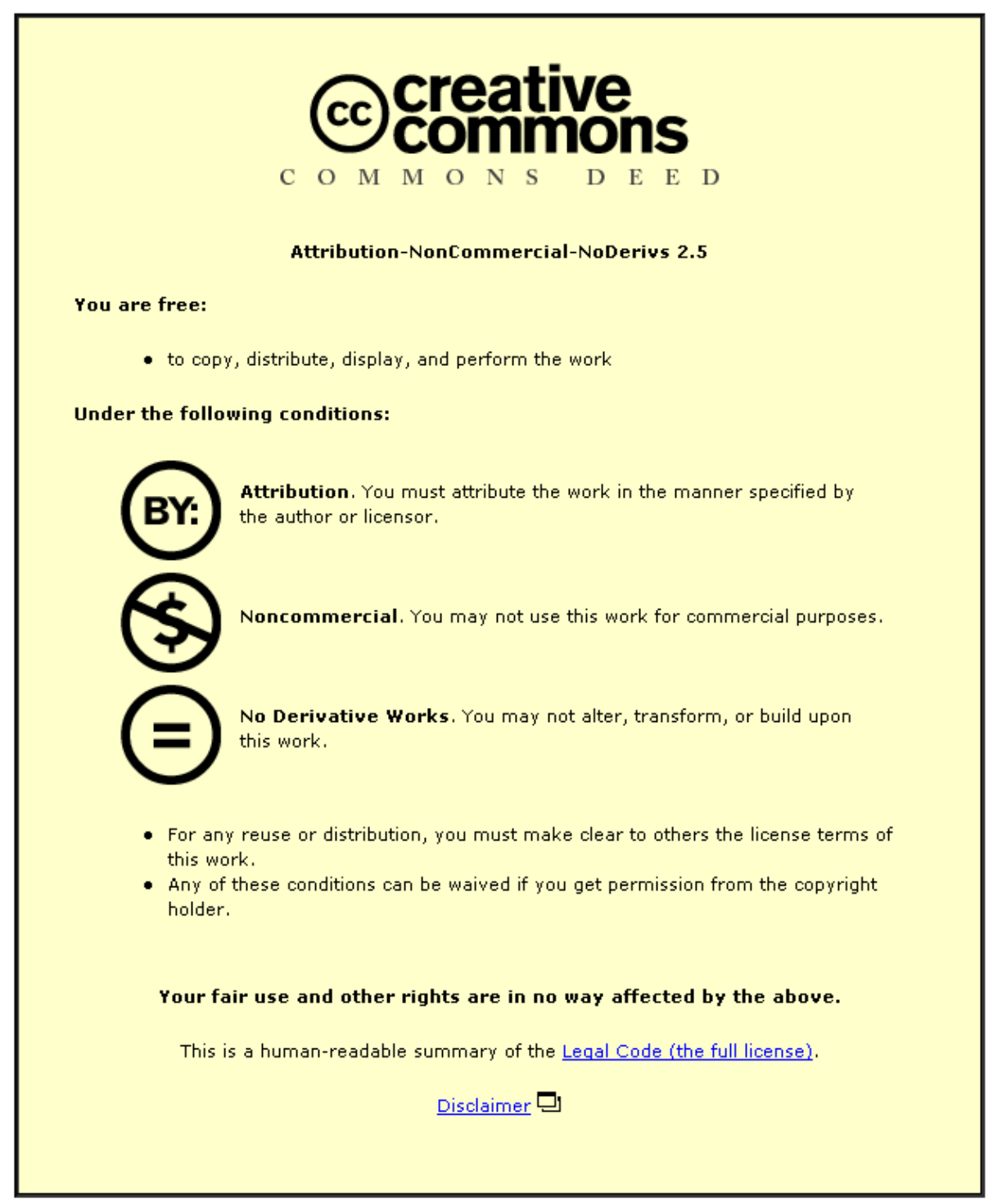

For the full text of this licence, please go to: http://creativecommons.org/licenses/by-nc-nd/2.5/ 


\section{Elsevier Editorial System(tm) for Materials Science \& Engineering A Manuscript Draft}

Manuscript Number: MSEA-D-09-02777R1

Title: The Effect of Interface Topography for Ultrasonic Consolidation of Aluminium

Article Type: Research Paper

Keywords: Ultrasonic Consolidation; Aluminium Alloys; Light Microscopy; Surface Roughness; Welding; Additive Manufacturing

Corresponding Author: Mr. Ross James Friel, B.Eng, M.Sc

Corresponding Author's Institution: Loughborough University

First Author: Ross James Friel, B.Eng, M.Sc

Order of Authors: Ross James Friel, B.Eng, M.Sc; Kenneth E Johnson, Ph.D, M.Eng, B.Sc; Phill M Dickens, Ph.D, B.Sc; Russell A Harris, Ph.D, B.Eng

Abstract: Ultrasonic Consolidation (UC) is an additive manufacturing technology which is based on the sequential solid-state ultrasonic welding of metal foils. UC presents a rapid and adaptive alternative process, to other metal-matrix embedding technologies, for 'smart' metal composite material production. A challenge that exists however relates to optimising, for bond density and plastic flow, the interlaminar textures themselves that serve as the contact surfaces between the foils.

UC employs a sonotrode connected to a transducer to exude ultrasonic energy into the metal foil being sequentially deposited. This sonotrode to metal contact imparts a noteworthy topology to the processed metals surface that in turn becomes the crucial substrate topology of the subsequent layers deposition. This work investigated UC processed Al 3003 samples to ascertain the effect of this imparted topology on subsequent layer deposition. Surface and interlaminar topology profiles were characterised using interferometry, electron and light microscopy. The physical effect of the topology profiles were quantified via the use of peel testing.

The imparted topology profile was found to be of fundamental significance to the mechanical performance and bond density achieved within the bulk laminate during UC. The UC process parameters and sonotrode topology performed a key role in modifying this topology profile. The concept of using a specifically textured sonotrode to attain desired future smart material performance via UC is proposed by the authors. 


\title{
The Effect of Interface Topography for \\ Ultrasonic Consolidation of Aluminium
}

\author{
*R. J. Friel ${ }^{\text {a }}$, K. E. Johnson ${ }^{\text {b }}$, P. M. Dickens ${ }^{\text {a }}$ and R. A. Harris ${ }^{\text {a }}$ \\ ${ }^{a}$ Wolfson School of Mechanical \& Manufacturing Engineering, Loughborough University, Loughborough, LE11 \\ 3TU, UK. \\ Email -*R.J.Friel@lboro.ac.uk; P.Dickens@lboro.ac.uk; R.A.Harris@lboro.ac.uk \\ b Solidica Inc., 1194 Oak Valley Drive Suite 80, Ann Arbor, Michigan, 48108-8942, USA. \\ Email - ken.johnson@solidica.com \\ *Corresponding Author: Mr. Ross James Friel (Tel: +44 (0)1509 227680 Fax: +44 (0)1509 227549)
}

\begin{abstract}
Ultrasonic Consolidation (UC) is an additive manufacturing technology which is based on the sequential solid-state ultrasonic welding of metal foils. UC presents a rapid and adaptive alternative process, to other metal-matrix embedding technologies, for 'smart' metal composite material production. A challenge that exists however relates to optimising, for bond density and plastic flow, the interlaminar textures themselves that serve as the contact surfaces between the foils.
\end{abstract}

UC employs a sonotrode connected to a transducer to exude ultrasonic energy into the metal foil being sequentially deposited. This sonotrode to metal contact imparts a noteworthy topology to the processed metals surface that in turn becomes the crucial substrate topology of the subsequent layers deposition. This work investigated UC processed Al 3003 samples to ascertain the effect of this imparted topology on subsequent layer deposition. Surface and interlaminar topology profiles were characterised using interferometry, electron and light microscopy. The physical effect of the topology profiles were quantified via the use of peel testing.

The imparted topology profile was found to be of fundamental significance to the mechanical performance and bond density achieved within the bulk laminate during UC. The UC process parameters and sonotrode topology performed a key role in modifying this topology profile. The concept of using a specifically textured sonotrode to attain desired future smart material performance via UC is proposed by the authors. 
Keywords: Ultrasonic Consolidation; Aluminium Alloys; Light Microscopy; Surface Roughness; Welding; Additive Manufacturing

\section{INTRODUCTION}

The Ultrasonic Consolidation (UC) process (see Figure 1) was invented and patented by Solidica Inc., USA [1] and is an additive manufacturing technology. UC combines Ultrasonic Welding (USW) with Computer Numerical Control (CNC) machining by using an ultrasonic welder to join metal foils, layer by layer, and then periodic contour $\mathrm{CNC}$ milling to create a solid metal 3D component [2] that replicates the original 3D CAD model. This permits the production of a diverse array of net shape components.

During UC, energy generated from an ultrasonic transducer is transferred to a work piece through a roughened sonotrode in the form of ultrasonic oscillation. These oscillations, combined with a compressive normal force from the sonotrode, allow interlaminar metal flow with associated localised heating which is much lower than the melting temperature (typically $<50 \%$ of the melting temperature), resulting in true metallurgical bonding at the consolidation interface without melting and at relatively low pressures (typically <300 kPa).

\section{Figure 1 - Schematic diagram of the Ultrasonic Consolidation process}

There are several benefits of UC over traditional manufacturing processes. Two key abilities of the UC process are the ability to fully embed objects into a metal matrix without the need for high temperatures or pressures and the ability to bond, thermally and mechanically, dissimilar materials together [3]. The embedment of objects is achieved during UC processing due to a significant lower level of temperature (USW of metals is a solid state process) combined with high plastic flow in the interlaminar region occurring during foil deposition. This phenomenon has previously been referred to as 'acoustic softening' [4]. This attribute can, and has, been exploited to allow the embedding of active [5, 6], passive [7] and optical fibres [8], as well as various other components [6, 9], within an Al matrix. UC presents a highly attractive alternative, to other metal-matrix embedding technologies with associated high-temperatures and/or high-pressures, for the production of high accuracy smart metal matrix composites.

Unlike most traditional metal USW processes, UC requires the "area" bonding of multiple layers of metal material as opposed to a single weld between two materials $[10,11]$. The sonotrode contact with the metal surface, (performed under pressure and with an oscillatory motion at ultrasonic frequency), creates a deformed surface similar in topography to the sonotrode surface that results from the sonotrode contact imprint. Subsequent metal material is 
bonded directly to this roughened surface. The uneven roughened substrate surface that each new layer is bonded to is theorised to lead to levels of porosity between the foil layers of an Ultrasonically Consolidated component. Interlaminar porosity in UC can result in reduced mechanical performance, when compared to monolithic structures of the same material $[12,13]$. A certain level of surface roughness on the sonotrode is a necessity in UC and is required to ensure adequate transfer of the mechanical energy from the sonotrode into the metal; which ensures adequate bonding during the UC process [14] within the interlaminar region.

The resulting surface topography produced by direct sonotrode to metal foil material contact is likely to have a role in the interlaminar bonding dynamics of the UC laminate. This study has used UC to produce Al 3003 samples with various process parameters to explore the relation of substrate topography and bond strength. These samples have been mechanically, optically and metrologically characterised and a summary of their influence within a UC component has been compiled.

\section{METHODOLOGY}

\subsection{MATERIALS}

The sample specimens were produced using two varieties of aluminium 3003 alloy foil with $100 \mu \mathrm{m}$ thickness and $25.4 \mathrm{~mm}$ width. Al 30030 is annealed and H18 is fully strain hardened. The chemical composition and mechanical properties of $\mathrm{Al} 30030$ and $\mathrm{H} 18$ are stated in Table 1.

\section{Table 1 - Mechanical properties and composition of Al 3003}

\subsection{SONOTRODE TOPOLOGY TRANSFER MONITORING}

To determine the level and nature of the topology transfer from the sonotrode to the foil material, two differently engineered sonotrode textures were manufactured and then used to fabricate a UC specimen. The machine used for this work was a Form-ation ${ }^{\mathrm{TM}}$ UC machine (manufactured by Solidica, Inc. USA) with Ti-6Al-4V sonotrodes. This experimentation would elucidate on the interlaminar topology created during the UC process.

The key steps in this methodology were:

1. Texturing two different UC sonotrodes using both Electrical Discharge Machining (EDM) and Laser Etching (LE). 
2. Generate a 3D map of the sonotrode surface topology using white light interferometry.

3. Bond a layer of $\mathrm{Al} 3003 \mathrm{H} 18$ using both sonotrode texture types in turn.

4. Generate a 3D map of the residual surface topology and calculate surface roughness values.

5. View the interface using Scanning Electron Microscopy (SEM) to determine the effect on the interface region and interlaminar topology formation.

\subsubsection{Sonotrode Surface Texturing Application}

The sonotrode contact surface (refer to Figure 2) was modified using the previously mentioned methods of EDM and LE. Due to the unique equipment required for this texturing process the texturing treatment was performed by external commercial suppliers using their specialist facilities. In each case the specific texturing process that was used was deemed proprietary knowledge by the companies and thus the specific methods used were not disclosed to the author but the resultant textures were fully topologically characterised.

Figure 2 - Sonotrode used in Form-ation ${ }^{\mathrm{TM}}$ UC system highlighting the sonotrode region that is in direct contact with the UC laminate that was textured using EDM and LE methods

\subsubsection{Three Dimensional Profiling of Sonotrode Surfaces}

After EDM and LE texturing, the sonotrode surfaces were measured to create a 3D scale representation of the surface allowing the calculation of various roughness parameters. The system used for performing the 3D measurements was a WYKO NT 8000 (Michigan Metrology Institute, USA) configured with a 5.1X objective lens. The specific operational parameters that were used are listed in Table 2.

Table 2 - WYKO NT 8000 system parameter settings

The collected 3D data was analysed with WYKO Vision software (version 3.60). The 3D measurements of surface roughness were taken from the complete micrograph area of the sample region. The quantitative value for the sonotrode roughness measurements were then specified as an average surface roughness value. 


\subsubsection{Optical Micrographs of Imprinted Topology}

After texturing and subsequent 3D surface roughness profiling, the sonotrodes were used to manufacture UC laminate samples utilising $\mathrm{Al} 3003 \mathrm{H} 18$ foil material. This allowed the foil interface to be optically assessed to determine topology transfer from the sonotrode to the Al laminate surface. The UC machine parameters that were used for these samples were based upon the common parameters that are recommended by Solidica for the selected material and are identified in Table 3 (note that a pre weld "tacking" stage was necessary to hold the foil in place during the full weld cycle).

\section{Table 3 - UC weld parameters (at $149^{\circ} \mathrm{C}$ ) for laminate samples used to determine sonotrode texture transfer}

\subsubsection{Scanning Electron Microscopy Analysis of Weld Cross-Section}

To determine the bond density produced using both types of sonotrode texture the cross sectioning of several UC samples was performed and analysed using SEM. This analysis was to gather evidence of the effect of the EDM and LE textures on the formation of voids at the UC weld interface. SEM using a LEO 340 machine at Loughborough University was utilised.

\subsection{INTERLAMINAR TOPOLOGY AND BONDING CHARACTERISATION}

To determine the effect of the topology transfer from the sonotrode to the foil material post UC processing, mechanical peel testing in addition to post peel testing surface profiling and optical microscopy were used. This allowed quantification of the sonotrode texturing effect, in combination with processing parameters, on UC manufactured samples.

\subsubsection{Sample Production for Interlaminar Characterisation}

Samples were produced on the Alpha UC machine based at Loughborough University (manufactured by Solidica, Inc. USA). The Alpha UC machine is a modified $3.3 \mathrm{~kW}$ ultrasonic seam welder which has a rotating tool steel sonotrode that oscillates at a frequency of $20 \mathrm{kHz}$. The Alpha UC machine had been used in several previously published works, [5, 6, 8, 12, 15-18], and had three main operating parameters; that can be set individually. The parameters are amplitude of sonotrode oscillation $(\mu \mathrm{m})$, welding speed $(\mathrm{mm} / \mathrm{s})$, and weld force $(\mathrm{N})$. The parameters used to produce the samples are shown in Table 4. 
Table 4 - The combinations of processing parameters used to produce the ultrasonically consolidated peel testing samples

Peel strength was assessed using tensile testing equipment. Cross-sectional analysis of the UC weld was analysed using optical microscopy. The 3D interlaminar residual surface topography was monitored using white light interferometry in combination with optical microscopy. The key steps in this methodology were:

1. Producing UC samples with the Alpha UC machine using Al 30030 and various process parameters (Table $4)$.

2. Cross-sectioning of samples and evaluation of the weld density using optical microscopy.

3. Perform peel testing on UC samples to measure the mechanical peel strength of the samples.

4. Generate 3D profiles of the Al 30030 interlaminar residual surface topology using white light interferometry and analyse the surface using optical microscopy.

\subsubsection{Optical Weld Density Analysis}

To quantify the density of bonding, a measurement technique was used to calculate the area of direct contact points after UC $[12,13]$. As for similar analysis, the term Linear Weld Density (LWD) was used to represent the percentage of bonded length, $L b$, as a proportion of the total bond interface length, $L c$, for a given UC sample, and was expressed as:

$$
\operatorname{LWD}(\%)=\left[\frac{L b}{L c}\right] \times 100
$$

\section{Equation 1 - The linear weld density equation}

Two samples for each set of processing parameters (Table 4) were sectioned into start middle and finish sections (see Figure 3) which were then mounted in a thermosetting polymer resin. Each sample was then gradually polished to 1 $\mu \mathrm{m}$. An optical light microscope with a $\times 200$ magnification lens was used to analyse the samples and obtain images for LWD assessment. Seven images, along the bond interface, for each mounted sample section were taken. 
Figure 3 - Schematic showing specimen sample extraction regions for microscopic analysis to determine LWD

The images were each assessed to determine the bonded length $(L b)$ and interface length $(L c)$ before calculating the LWD (see Equation 1). For all the images obtained for each sample, consolidated using a specific set of processing parameters, an average of the LWD was calculated for the monolithic Al 30030 samples produced using those specific processing parameters.

\subsubsection{Peel Testing}

The peel testing was carried out in accordance with BS EN2243-2:1991 [14, 18]. The peel testing allowed for bond quality to be quantitatively analysed by assessing a samples average resistance to peeling for the given UC parameters. Three Al $30030 \mathrm{UC}$ samples for each of the process parameter combinations in Table 4 were peel tested and the average peel strength was calculated for each set of parameters.

A peel testing apparatus was attached to a Lloyd Instruments LRX material testing machine and used to peel samples that had been mounted as shown in Figure 4. The un-bonded foil length used to load the UC sample was $100 \pm 5 \mathrm{~mm}$ in length. The testing parameters used during the peel testing were to use a tensile loading speed of $50 \mathrm{~mm} / \mathrm{min}$ and the testing was set to stop when the peel force dropped to $10 \%$ of the maximum load measured.

Figure 4 - Schematic of the sample mounting technique within the peel testing apparatus

\subsubsection{Optical Interlaminar Surface Topology Analysis}

A Leica DM 6000 optical microscope with image capture was used to optically analyse and document the UC weld interface of the previously peel tested samples. Three samples for each set of processing parameters (Table 4) were peeled and then the area of foil removal was optically analysed to determine the visual effect on the interlaminar topography, created during UC, for various processing parameters. A schematic representation of the analysed areas after peel testing is shown in Figure 5.

Figure 5 - Photo and Schematic of the optical profile measurement regions used on the peeled Al 30030 samples 


\subsubsection{Three Dimensional Profiling of Interlaminar Surfaces}

To quantify the interlaminar topography of the UC samples produced using various processing parameters white light interferometry was used. This type of optical profiling allowed for accurate determination of the 3D $R_{a}(\mu \mathrm{m})$ values for the interlaminar structure for various processing parameters as well as creating a topographical profile of the area of interest. The analysed areas were the same as those shown in Figure 5.

The optical profiling system used for taking the 3D measurements was a Zygo NewView 5000 with a $\times 10$ magnification objective lens. The processing variables used during the measurements are shown in Table 5; these parameters were set within the proprietary software (MetroPro version 8.1.5).

Table 5 - Zygo NewView 5000 system parameter settings

As with the optical topology measurement, each area for each sample was variable due to the variable nature of the 'teeth' profile produced during peel testing, however, Figure 5 shows the approximate area of measurement used for each sample. Three measurements were taken for each sample and the sample data was analysed using TalyMap Gold 4.1 software. The 3D $R_{a}$ values for the whole surface (known as the $S_{a}$ ) were measured using the software after this processing was complete.

All surface roughness measurements were taken at a temperature of $21 \pm 2{ }^{\circ} \mathrm{C}$ and each sample was thermally soaked at this temperature for at least 24 hours prior to measurement to ensure accuracy.

\section{RESULTS}

\subsection{MACROSCOPIC EFFECTS OF SONOTRODE TOPOLOGY}

\subsubsection{Sonotrode Surface Preparation and Three Dimensional Surface Profiling}

Two sonotrodes were successfully textured via EDM and LE. Both the EDM and LE textured sonotrodes were successfully 3D mapped using the WYKO NT 8000 optical profiling system. This profile data was then analysed using the WYKO software and the average surface roughness values for the sonotrode are given in Table 6 . The preUC as-received foil texture data was also obtained and given in Table 6. 
Table 6 - $R_{\mathrm{a}}$ and $\mathbf{R}_{\mathrm{q}}$ values for the sonotrode with LE surface, the sonotrode with EDM surface and the Pre-

\section{UC Foil}

A sample 3D profile of the LE and EDM sonotrode are shown in Figure 6 and Figure 7 respectively.

The LE surface had a more pronounced topology resulting in an $\mathrm{R}_{\mathrm{a}}$ value over twice that of the EDM textured sonotrode.

Figure 6 - Three dimensional optical profile of the LE sonotrode surface

The EDM surface was visually different to the LE textured sonotrode and was more uniform and less pronounced in its topology, resulting in a lower $\mathrm{R}_{\mathrm{a}}$ value than for the $\mathrm{LE}$ sonotrode.

Figure 7 - Three dimensional optical profile of the EDM sonotrode surface

\subsubsection{Optical Micrographs of Sonotrode Topology Imprint}

Topology transfer from the sonotrode to the processed foil was successfully documented using optical microscopy.

Figure 8 identifies the sonotrode texture type with the profile imparted to the foil material. The darker areas on the micrographs indicate the material that has been plastically deformed by the sonotrode and its resultant texture. The lighter areas indicate regions of foil material that have remained in an as-rolled prior state during UC processing.

Figure 8 - LE (a) and EDM (b) sonotrode textures and the optical micrographs of the residual topologies left behind. The light areas are an indication of void volume/unprocessed foil material 


\subsubsection{Scanning Electron Microscopy of Ultrasonic Consolidation Weld Cross-Section}

SEM micrographs of sample five layer stack cross-sections were successfully obtained. The sample stacks were produced with both the LE and EDM sonotrode and the results compared. These results showed the influence of the transferred topology on the apparent bond density achieved during UC. Specimens produced with the rougher LE sonotrode had more voids at the bond interface than samples produced with the smoother EDM textured sonotrode (see Figure 9).

Figure 9 - (a) Cross section of top of a five layer stack of foil produced from LE textured sonotrode; (b) Cross section of a five layer stack produced from EDM textured sonotrode

\subsection{INTERLAMINAR TOPOLOGY AND BONDING CHARACTERISATION}

\subsubsection{Optical Weld Density Analysis}

The samples were successfully cross-sectioned and analysed using optical microscopy. The LWD was then calculated for each sample set for each combination of processing parameters and the average LWD's were calculated and are displayed graphically in Figure 10.

Figure 10 - A graph showing the average LWD results for UC Al 30030

The general trend was that higher amplitude and weld force processing parameters resulted in a higher LWD. However this was not the case for the highest weld force $(1335 \mathrm{~N})$ which resulted in some of the lowest LWD. The increasing amplitude did still have an effect on improving the LWD in this case.

\subsubsection{Peel Testing}

The peel testing was carried out and maximum peel loads have been graphically represented in Figure 11.

Figure 11 - A graph showing the average maximum peel load for UC Al 30030 
The higher the amplitude and weld force the greater the maximum peel load tended to be. This related to the LWD; a greater LWD generally resulted in a greater maximum peel load for the given process parameters. The increase in weld force and amplitude resulted in a trend in the peeling profile of the samples from a ductile failure mode to a more brittle failure mode (Figure 12). For a processing weld force of $895 \mathrm{~N}$ the LWD was higher than that for the $1335 \mathrm{~N}$ weld force, however the maximum peel load was less than that for the $1335 \mathrm{~N}$ samples.

Figure 12 - The peeling load vs. extension graph showing the two different forms of failure mode

\subsubsection{Optical Interlaminar Surface Topology Analysis}

The residual topology of the interlaminar foil interface was successfully documented using optical microscopy, post peel testing. The analysis showed regions of material that appeared to be unprocessed during the UC cycle similar to Figure 8. These regions of unprocessed foil were found to reduce in size with higher amplitude (Figure 13). The regions of unprocessed foil appeared larger in area when lower processing amplitudes were used during UC. For samples produced using higher processing amplitude the areas of unprocessed foil appeared smaller in their individual area but were more numerous.

Figure 13 - Optical micrographs at 5x magnification of an Al 30030 interlaminar Ultrasonically Consolidated surface (a) $10.41 \mu \mathrm{m}$ amplitude (b) $14.26 \mu \mathrm{m}$ amplitude

3D micrographs were compiled to document the peak and valley topography and the unprocessed regions of foil material (example given in Figure 14). The unprocessed foil was seen to lie at the bottom of these valleys, while the processed foil acted as the peaks of the surface. The process parameters used to produce the sample were $1190 \mathrm{~N}$ weld force and $10.41 \mu \mathrm{m}$ amplitude.

Figure 14 - A three dimensional optical micrograph of an Al 30030 interlaminar Ultrasonically Consolidated surface showing processed and unprocessed foil regions 
Figure 15 shows the optical micrographs of the residual topology (a) and the contact pattern on the underside of the peeled top layer (b) post mechanical peel testing. The optical micrograph of the void area is shown in (c) along with $\mathrm{R}_{\mathrm{a}}$ and $\mathrm{R}_{\mathrm{q}}$ values for the whole processed region (including voids) and the unprocessed void region.

Figure 15 - Optical micrographs of the sonotrode texture imprint onto top foil (a), the residual texture (b) on bottom of tape (after subsequent layer bonding and forced separation via mechanical peel testing) and the void area - that remains in the as-rolled state (c)

\subsubsection{Three Dimensional Profiling of Interlaminar Surfaces}

The optical 3D profiling of the interlaminar surfaces of Al 30030 peeled samples was successfully carried out. The profiles showed that as the processing amplitude and weld force were increased the surface became, generally, smoother and more uniform in its overall topology.

Figure 16 shows a typical 3D profile of a sample produced at a lower amplitude and weld force. The surface was observed to have a dark region that represented a valley where the surface was relatively smooth. This smooth region was the unprocessed foil that was similar to Figure 14 and was present as a void in the bond interface when crosssectioned and analysed.

Figure 16 - Three dimensional optical profile of the interlaminar region for an Al 30030 sample produced via the parameters: $10.41 \mu \mathrm{m}, 1040 \mathrm{~N} 34.5 \mathrm{~mm} / \mathrm{s}$

Figure 17 shows a typical 3D optical profile of a sample produced at a higher processing amplitude and weld force. The profile showed that the overall surface roughness was lower and there were fewer regions of the relatively smooth unprocessed material valleys.

Figure 17 - Three dimensional optical profile of the interlaminar region for an Al 30030 sample produced via the parameters: $14.26 \mu \mathrm{m}, 1190 \mathrm{~N} 34.5 \mathrm{~mm} / \mathrm{s}$

The average 3D surface roughness $\left(R_{a}\right)$ measurement values obtained from the optical profiling are shown in Table 7. 
Table 7 - Average Al 3003-0 interlaminar $R_{a}$ measurements for various UC process parameters at $34.5 \mathrm{~mm} / \mathrm{s}$ welding speed

\section{DISCUSSION AND FURTHER WORK}

\subsection{SONOTRODE EFFECT ON MATERIAL TOPOLOGY}

Texturing of the sonotrodes and then topology imprint analysis proved that the residual topology on the foil material is intrinsically linked to the sonotrode topology. The rougher and less uniform LE textured sonotrode created a surface that was rougher and less uniform than for material processed with the EDM textured sonotrode. The LE sonotrode resulted in topography with larger areas of foil material that were not processed in comparison with the EDM sonotrode (Figure 8). This greater volume of un-processed foil then had a cumulative effect on the bond density achieved during multiple stacking via UC; the LE sonotrode produced a UC laminate with a greater void volume (Figure 9). This greater void volume has been shown to result in lower mechanical performance of the UC laminates $[12,13]$ and is thus unfavourable for the majority of manufacturing situations.

To further elucidate on the topology transfer effect on the foil material and to aid this discussion further work was performed. Commercially pure Ti foil material and an Al foil (3003 - H18) were UC processed (see Table 3 for process parameters) and optically scanned (see Figure 18). In these experiments, the topology transfer was shown to be different when different foil materials were used. The sonotrode topology transfer was near $100 \%$ onto the $\mathrm{Al}$; this was likely due to the fact that the $\mathrm{Al} 3003-\mathrm{H} 18$ modulus and yield strength are low compared to the relatively hard Ti 6-4 sonotrode material. However when the relatively hard Ti foil was processed using the same sonotrode the topology transfer was visually and quantitatively lower than for the softer $\mathrm{Al} 3003-\mathrm{H} 18$, suggesting that a significant modulus difference must exist between the foil and sonotrode materials to attain a topology imprint. A more elevated processing temperature may help improve the topology transfer onto the Ti; however this was not investigated in the present work.

Figure 18 - Three dimensional optical profile of the residual topology on deposited foil following the imprint of the sonotrode topology to (a) aluminium $3003 \mathrm{H}-18$ foil and (b) commercially pure titanium foil

Topology transfer could also be improved for harder materials by using a harder sonotrode material and thus allowing for a designated level of topology transfer. Li, D. and Soar, R. [14] showed that a smoother, $(3.44 \mu \mathrm{m} \mathrm{R}$ in this case), sonotrode topology can result in inadequate bonding during UC; this was thought to be due to the lack of 
ultrasonic energy transfer into the foil material due to a high level of sonotrode slippage and energy loss when compared to a rougher material. The present work combined with previous work suggests that the sonotrode material texturing effect is of fundamental importance to the quality of components produced via UC. A too rough and nonuniform sonotrode (and hence processed material) topology has been shown to produce a high void volume whereas a too smooth surface topology results in a lack of bonding, likely due to minimal energy transfer to the interlaminar region. Further research should be performed to identify the optimal material topology to direct bonding during UC.

\subsection{MATERIAL TOPOLOGY EFFECT ON ULTRASONICALLY CONSOLIDATED SAMPLE PERFORMANCE}

As with previous work, $[12,13]$, the higher the LWD generally the higher the peel strength of UC samples was found to be. The optical microscopy and 3D profiling highlighted that when a relatively constant sonotrode topology is used, then the process parameters of amplitude and weld force have a significant effect on the interlaminar topology and bond density created during UC; (feed rate was not altered in this investigation). An increase in weld force and amplitude revealed that the un-bonded foil areas were reduced in maximum size but increased in number. This suggests that these two processing parameters have the effect of creating a more intimate contact between the foil layers during UC processing which results in a residual interlaminar bond of lower void volume. The LWD was not found to vary for the start middle and finish regions of the UC samples.

In this study the trend of higher weld force creating higher peel strength was not apparent when using the Alpha UC and a processing weld force of $1335 \mathrm{~N}$. A reason for this could be due to the relatively high weld force resulting in a reduction in the relative oscillatory motion of the sonotrode due to elevated levels of contact friction between the sonotrode and anvil/sample. This reduction in oscillatory motion would lower the relative motion of the unprocessed foil with the previously processed foil, which could result in a reduction in bonding density achieved.

The LWD was shown to increase with processing amplitude for samples welded at $34.5 \mathrm{~mm} / \mathrm{s}$. This increase is also shown via interlaminar microscopy and 3D optical profiling. The greater the processing amplitude used, the smaller the unprocessed foil areas within the sample became. This reduction in unprocessed material led to a greater LWD and hence a better peel test performance. A reason that the higher amplitude creates this more refined peak and valley profile is possibly due to the greater lateral movement of the sonotrode creating a wider surface to surface contact area between the sonotrode and the upper foil layer. The foil to foil contact area is also maximised due to the greater lateral movement of the second foil layer over the first. This greater lateral movement combined with greater weld force resulted in a smoother interlaminar topology and therefore a greater foil surface to surface real area of contact. 
During peel testing the structures with the smaller void areas and hence more contact points resulted in a greater resistance to tear propagation within the material. This was evident from the 'tear teeth' profile created when the sample failed during peeling. The samples with the smoother interlaminar topology resulted in a more brittle failure with only small teeth patterns, where as the samples with greater unprocessed foil areas resulted in tear teeth patterns that were more pronounced and indicated a more ductile failure mode.

From the 3D profiles it was evident that the 'peak and valley' surface created by the sonotrode on the foil was very complex and highly variable when 2D surface roughness traces were taken via the TalyMap Gold software. This high variability helps explain the high level of variance when calculating the LWD using perpendicular mounted sections. A more representative method of calculating the LWD could be to use a plan view of the weld area which would allow for the unprocessed foil material to be identified and a bonded to non-bonded ratio could be more accurately assessed. Due to the deformation effects of peeling the bonded foils from each other, a non-destructive method of analysing the unbounded foil area would be highly beneficial in terms of accuracy. Further research would be required to find a suitable non-destructive method.

Although the LWD of UC samples produced using a weld force of $895 \mathrm{~N}$ were generally higher than for $1335 \mathrm{~N}$ this did not result in a better peel test performance. This suggests that although LWD is important for bond strength there are additional mechanisms taking place during UC bonding that are not represented on the macro scale via optical visualisation and profiling.

\section{CONCLUSIONS}

This work showed the surface roughness and topology profile of the sonotrode are critical factors in relation to the peel strength and bond density of UC samples and this was due to the surface, and subsequent interlaminar topology, that was produced by the sonotrode onto the foil material. The processing settings used during UC were able to increase the level of bonded area, resulting in better peel testing performance; however this bonded area increase appeared to still be dependent on the sonotrode topology profile. Too high a $\mathrm{R}_{\mathrm{a}}$ value resulted in lower bonded areas as did too low a $\mathrm{R}_{\mathrm{a}}$ value.

Due to the highly variable profile of UC topology, 2D LWD measurement was particularly limited and quality control could be better performed via the use of peel testing combined with optical profiling and microscopy of the interlaminar region to create a 3D representation of LWD. A non-destructive method of 3D LWD calculation would be of benefit in the quality control of UC samples in the commercial environment. 
The sonotrode topology transfer was likely related to the stiffness of the build and sonotrode materials. Stiffer sonotrode materials combined with higher amplitude, weld force and temperature capabilities in UC equipment would likely improve the UC bonding with more difficult to process materials, such as Ti.

Due to the significant influence of the sonotrode topology on bond quality it was theorised that an optimised sonotrode topology could increase the effectiveness of UC bonding and possibly allow for an alteration to the UC processed sample properties. It would be of benefit to investigate various sonotrode topologies to attempt to optimise UC bonding. A specific sonotrode topology could be used to maximise the sonotrode intimate contact area during UC processing to help improve the energy transfer efficiency and the refinement of the interlaminar structure. This could potentially allow for denser and stronger components to be produced as well as allowing for a possible increase in processing speed which would help make UC even more attractive. The alteration and analysis of various UC sonotrode topologies is currently being researched at Loughborough University, in partnership with Solidica, with the ultimate goal of optimising the sonotrode topology to maximise UC components for their intended end use.

\section{ACKNOWLEDGEMENT}

This work was supported by the Engineering and Physical Science Research Council (EPSRC).

\section{REFERENCES}

1. D. White, USA Patent 6519500, 2003.

2. D. White, Adv. Mater. \& Process., 161 (2003) 64-65.

3. G.D. Janaki Ram, C. Robinson, Y. Yang, B.E. Stucker, Rapid Prototyp. J., 13 (2007) 226-235.

4. B. Langenecker, Sonics \& Ultrasonics IEEE Trans., 13 (1966) 1-8.

5. C.Y. Kong, R.C. Soar, P.M. Dickens, Compos. Struct., 66 (2004) 421-427.

6. C.Y. Kong, "Investigation of ultrasonic consolidation for embedding active/passive fibres in aluminium matrices", Wolfson School of Mechanical and Manufacturing Engineering, Loughborough University, UK. 2005. PhD Thesis.

7. Y. Yang, G.D. Janaki Ram, B.E. Stucker, J. Eng. Mater. \& Technol., 129 (2007) 538-549.

8. C.Y. Kong, R.C. Soar, Appl. Opt., 44 (2005) 6325-6333.

9. C. Mou, P. Saffari, D. Li, K. Zhou, L. Zhang, R. Soar, I. Bennion, Meas. Sci. \& Technol., 20 (2009) 034013.

10. R. Jahn, R. Cooper, D. Wilkosz, Metall. \& Mater. Trans. A, 38 A (2007) 570-583. 
11. H.P.C. Daniels, Ultrasonics, (1965) 190-196.

12. C.Y. Kong, R.C. Soar, P.M. Dickens, Proc. IMechE Pt. C: J. Mech. Eng. Sci., 219 (2005) 83-91.

13. G.D. Janaki Ram, Y. Yang, J. George, C. Robinson, B.E. Stucker, Solid Freeform Fabrication Proceedings, Austin, TX, USA, August 2006, pp. 692-708.

14. D. Li, R. Soar, J. Mater. Process. Technol., 209 (2008) 1627-1634.

15. D. Li, R.C. Soar, Mater. Sci. \& Eng.: A, 498 (2008) 421-429.

16. C.Y. Kong, R.C. Soar, Mater. Sci. \& Eng.: A, 412 (2005) 12-18.

17. C.Y. Kong, R.C. Soar, P.M. Dickens, Mater. Sci. \& Eng.: A, 363 (2003) 99-106.

18. C.Y. Kong, R.C. Soar, P.M. Dickens, J. Mater. Process. Technol., 146 (2004) 181-187.

\section{LIST OF FIGURES}

Figure 1 - Schematic diagram of the Ultrasonic Consolidation process

Figure 2 - Sonotrode used in Form-ation ${ }^{\mathrm{TM}} \mathrm{UC}$ system highlighting the sonotrode region that is in direct contact with the UC laminate that was textured using EDM and LE methods

Figure 3 - Schematic showing specimen sample extraction regions for microscopic analysis to determine LWD

Figure 4 - Schematic of the sample mounting technique within the peel testing apparatus

Figure 5 - Photo and Schematic of the optical profile measurement regions used on the peeled Al 30030 samples

Figure 6 - Three dimensional optical profile of the LE sonotrode surface

Figure 7 - Three dimensional optical profile of the EDM sonotrode surface

Figure 8 - LE (a) and EDM (b) sonotrode textures and the optical micrographs of the residual topologies left behind. The light areas are an indication of void volume/unprocessed foil material

Figure 9 - (a) Cross section of top of a five layer stack of foil produced from LE textured sonotrode; (b) Cross section of a five layer stack produced from EDM textured sonotrode

Figure 10 - A graph showing the average LWD results for UC Al 30030

Figure 11 - A graph showing the average maximum peel load for UC Al 30030

Figure 12 - The peeling load vs. extension graph showing the two different forms of failure mode 
Figure 13 - Optical micrographs at 5x magnification of an Al 30030 interlaminar Ultrasonically Consolidated surface (a) $10.41 \mu \mathrm{m}$ amplitude (b) $14.26 \mu \mathrm{m}$ amplitude

Figure 14 - A three dimensional optical micrograph of an Al 30030 interlaminar Ultrasonically Consolidated surface showing processed and unprocessed foil regions

Figure 15 - Optical micrographs of the sonotrode texture imprint onto top foil (a), the residual texture (b) on bottom of tape (after subsequent layer bonding and forced separation via mechanical peel testing) and the void area - that remains in the as-rolled state (c)

Figure 16 - Three dimensional optical profile of the interlaminar region for an Al 30030 sample produced via the parameters: $10.41 \mu \mathrm{m}, 1040 \mathrm{~N} 34.5 \mathrm{~mm} / \mathrm{s}$

Figure 17 - Three dimensional optical profile of the interlaminar region for an Al 30030 sample produced via the parameters: $14.26 \mu \mathrm{m}, 1190 \mathrm{~N} 34.5 \mathrm{~mm} / \mathrm{s}$

Figure 18 - Three dimensional optical profile of the residual topology on deposited foil following the imprint of the sonotrode topology to (a) aluminium 3003 H-18 foil and (b) commercially pure titanium foil

\section{LIST OF TABLES}

Table 1 - Mechanical properties and composition of $\mathrm{Al} 3003$

Table 2 - WYKO NT 8000 system parameter settings

Table 3 - UC weld parameters (at $149^{\circ} \mathrm{C}$ ) for laminate samples used to determine sonotrode texture transfer

Table 4 - The combinations of processing parameters used to produce the ultrasonically consolidated peel testing samples

Table 5 - Zygo NewView 5000 system parameter settings

Table $6-\mathrm{R}_{\mathrm{a}}$ and $\mathrm{R}_{\mathrm{q}}$ values for the sonotrode with LE surface, the sonotrode with EDM surface and the Pre-UC Foil

Table 7 - Average Al 3003-0 interlaminar $\mathrm{R}_{\mathrm{a}}$ measurements for various UC process parameters at $34.5 \mathrm{~mm} / \mathrm{s}$ welding speed 
Oscillation

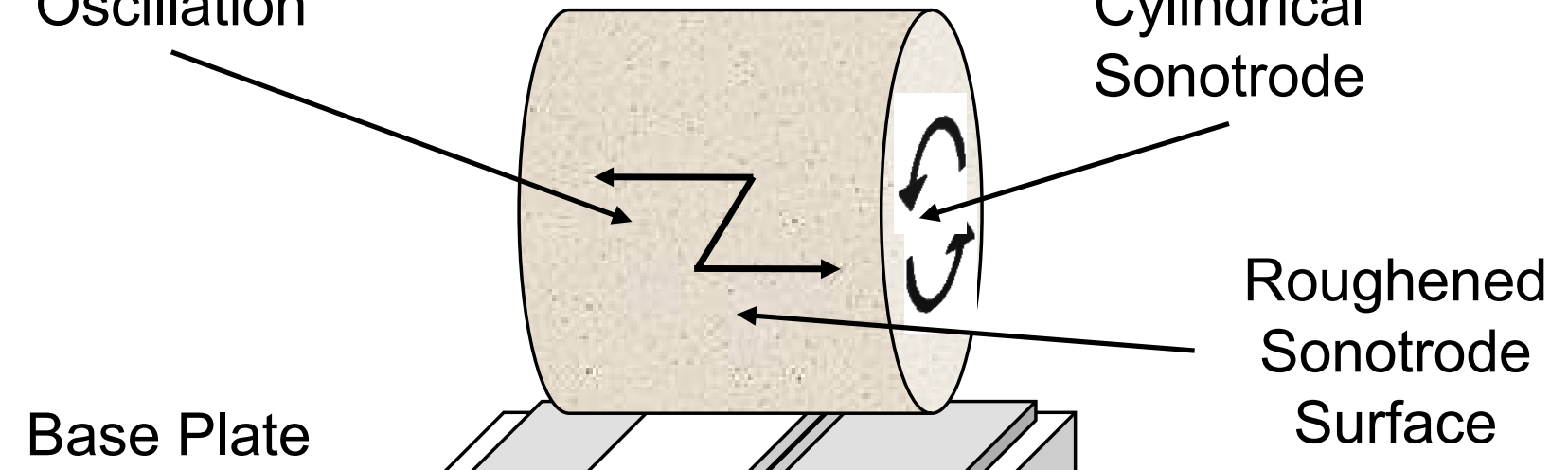

Foil/Foil Interface

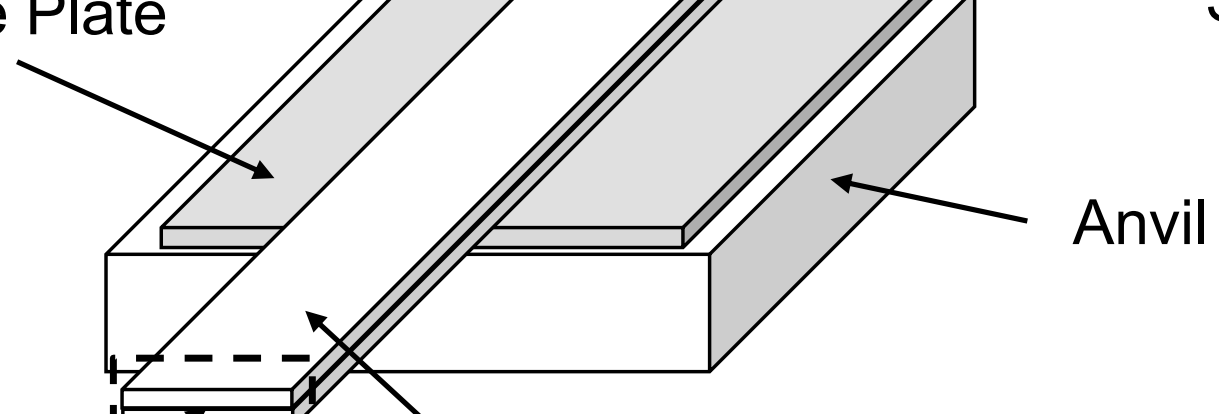

Clamping

Force from

Sonotrode

Foil/Foil Interface

Roughened Foil Surface due to Direct Sonotrode Contact

Metal

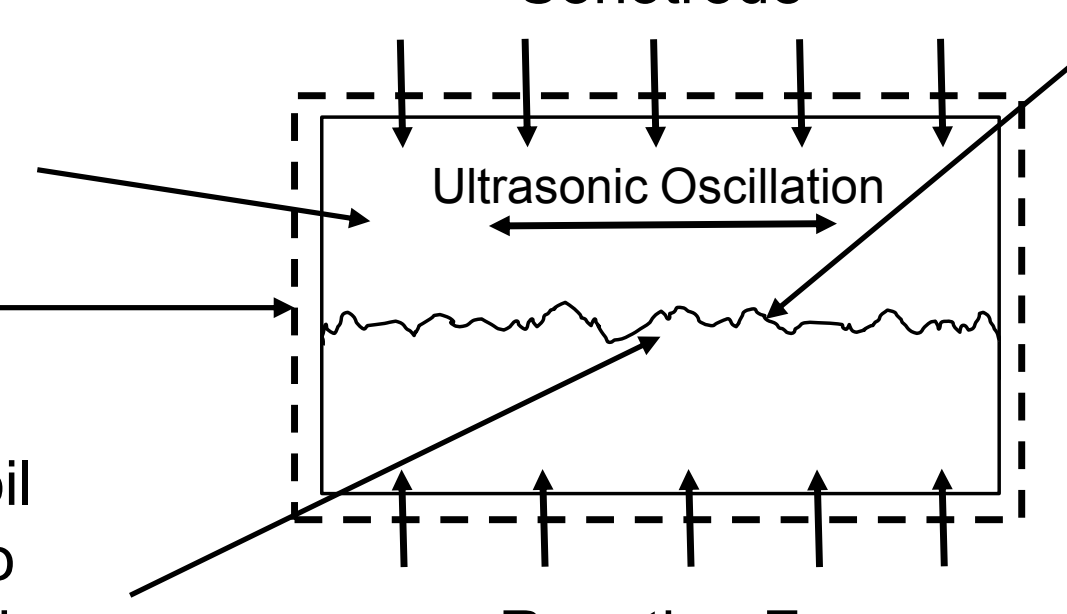

Reaction Force from Anvil

Figure 1 - Schematic diagram of the Ultrasonic Consolidation process 


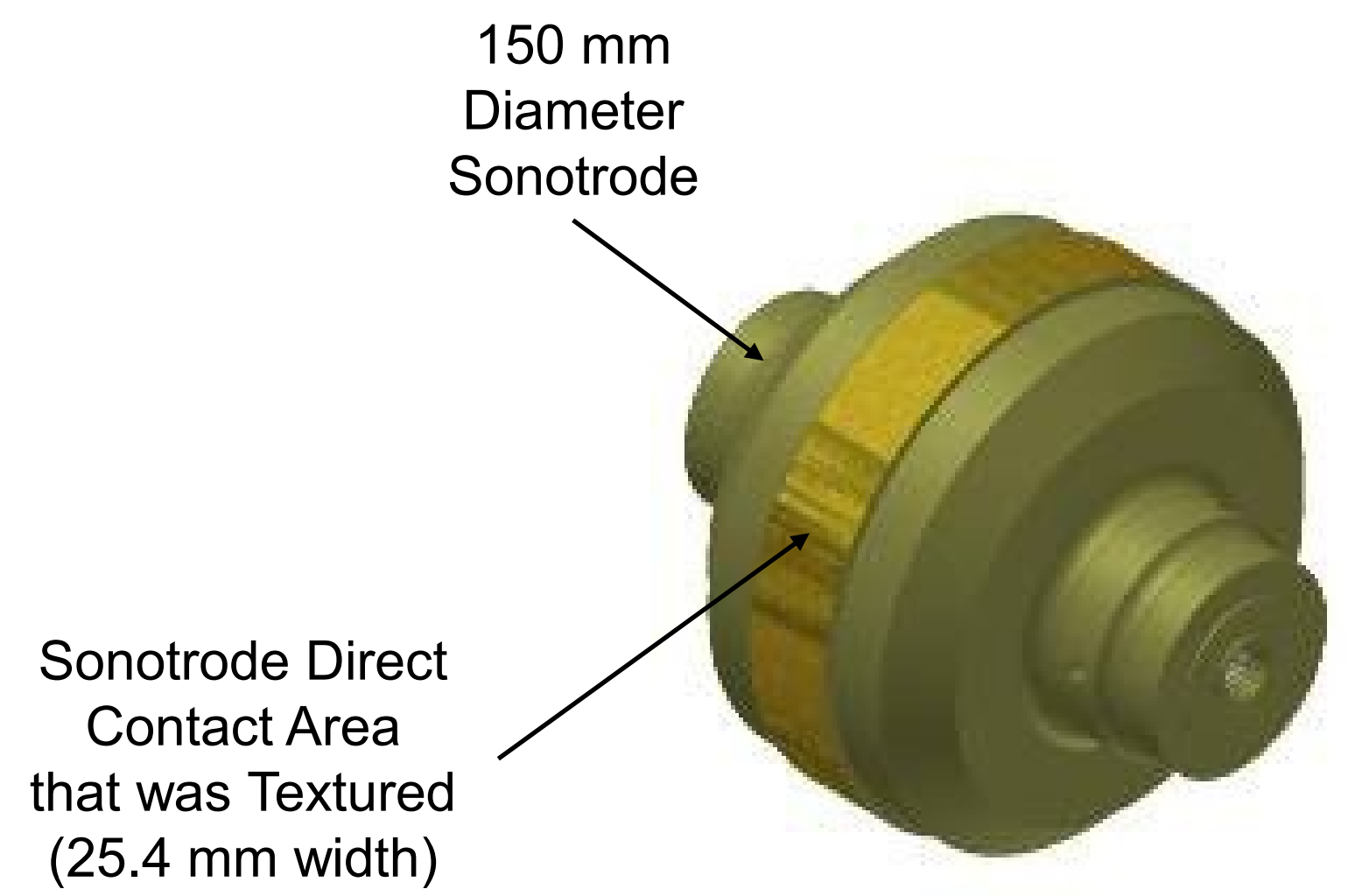

Figure 2 - Sonotrode used in Form-ation ${ }^{\mathrm{TM}}$ UC system highlighting the sonotrode region that is in direct contact with the UC laminate that was textured using EDM and LE methods 


\section{Al 30030 Foils}

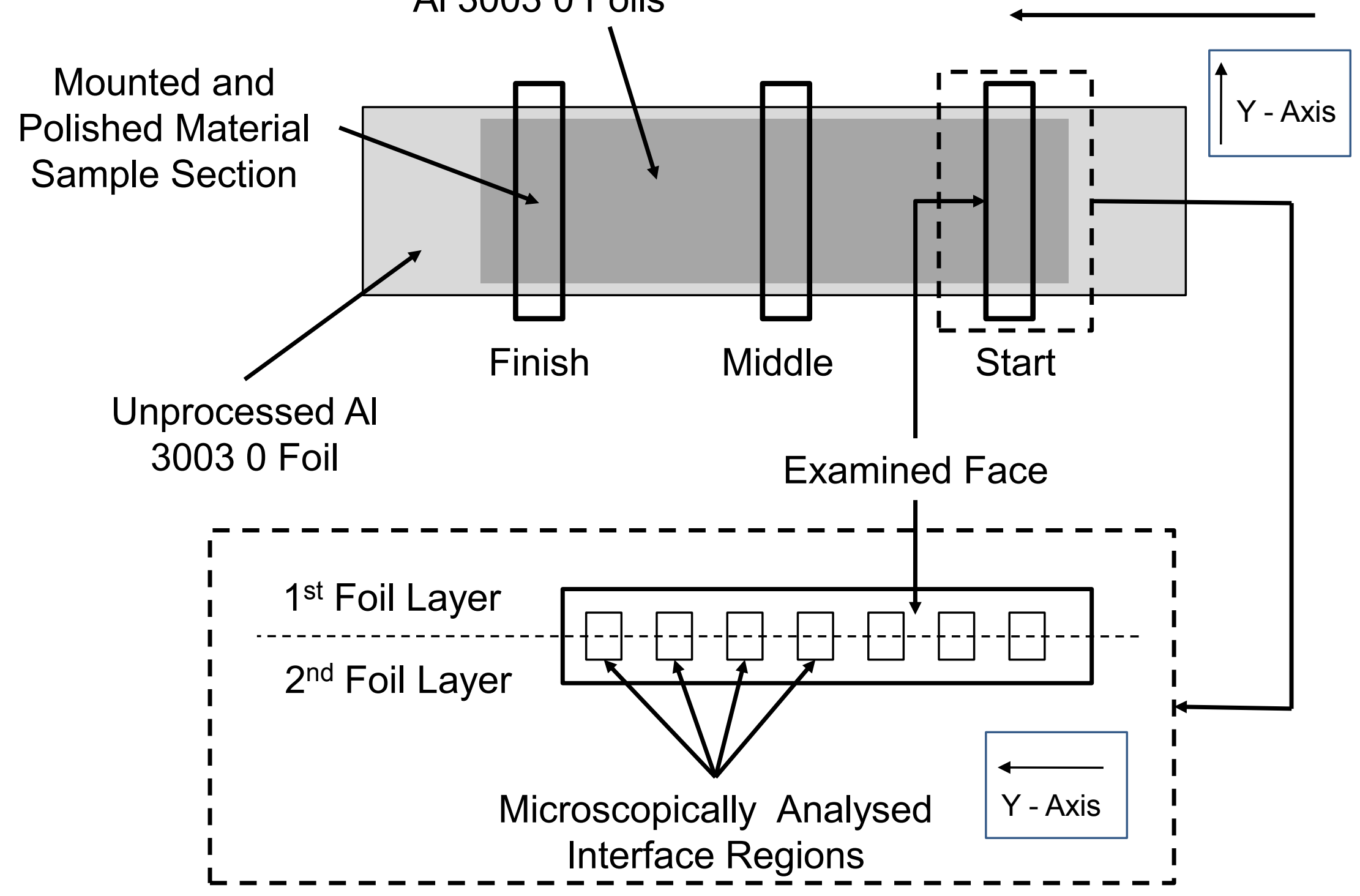

Figure 3 - Schematic showing specimen sample extraction regions for microscopic analysis to determine LWD 
Movement from the Testing Machine

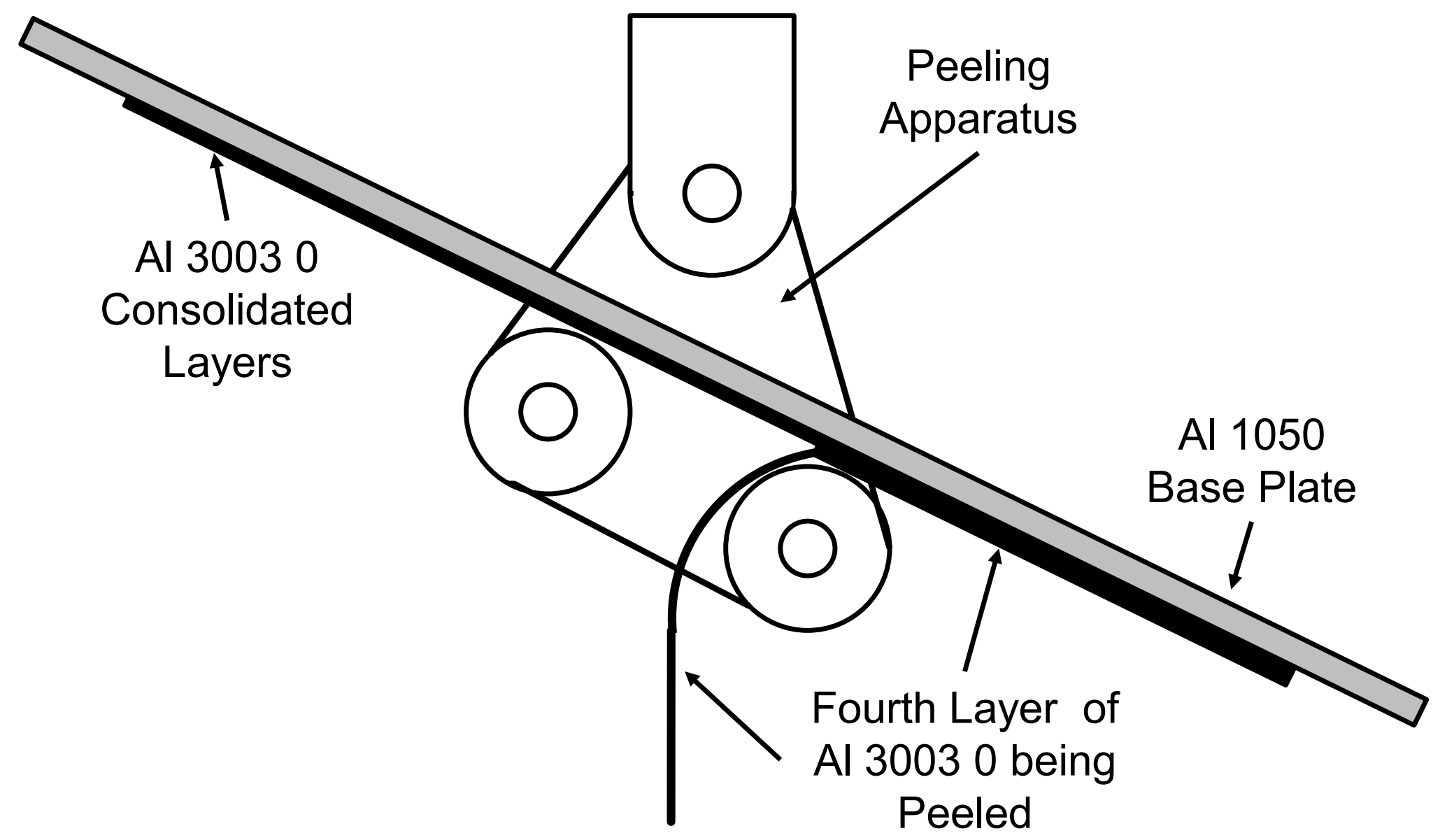

Held Stationary by the Clamp

Figure 4 - Schematic of the sample mounting technique within the peel testing apparatus 


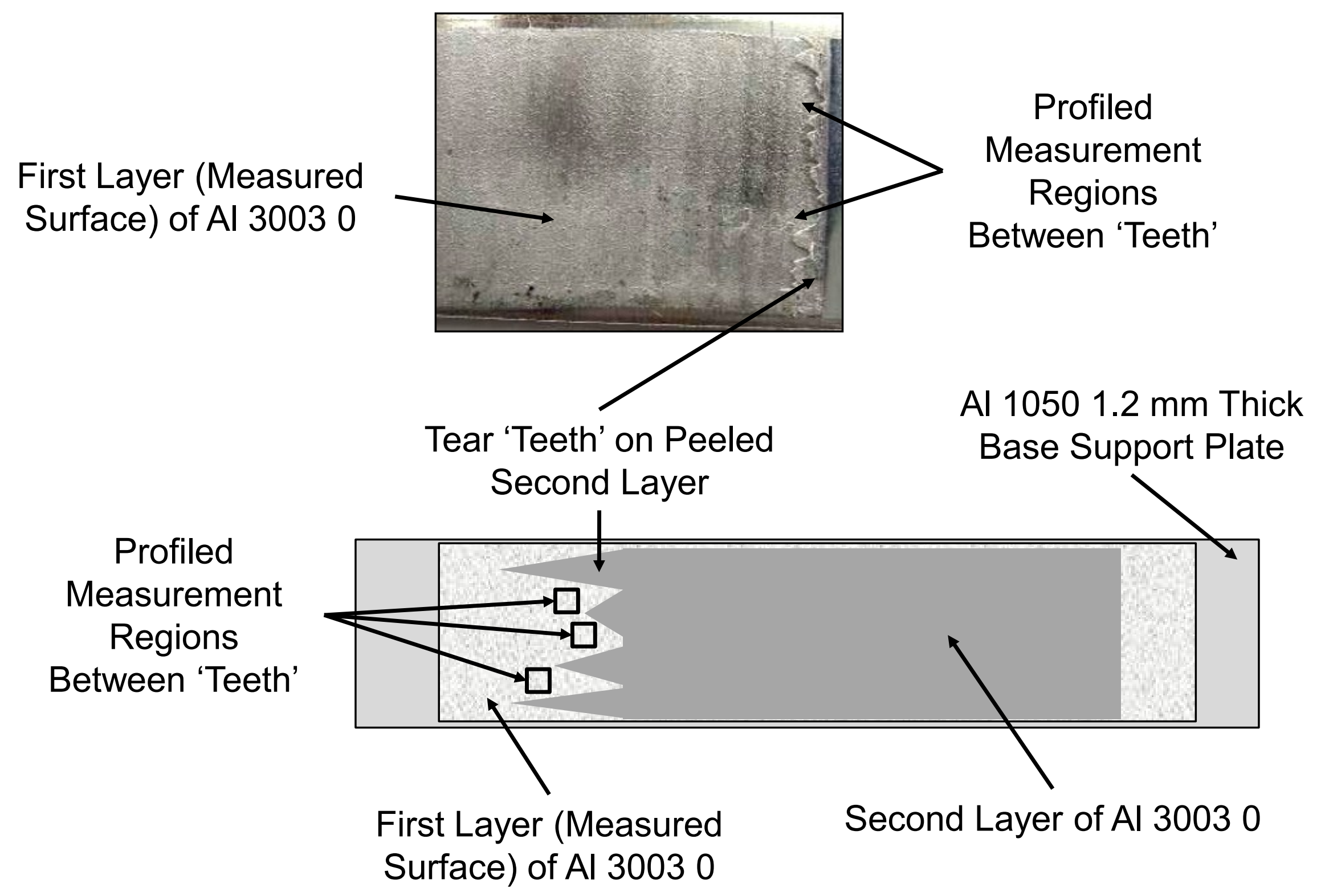

Figure 5 - Photo and Schematic of the optical profile measurement regions used on the peeled Al 30030 samples 


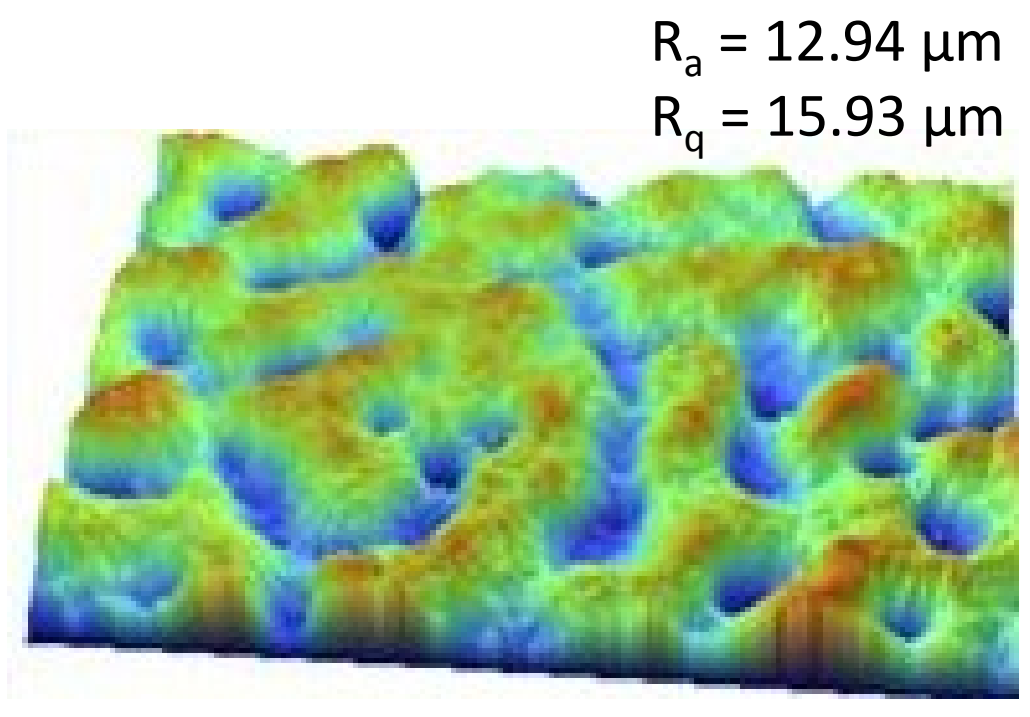

Figure 6 - Three dimensional optical profile of the LE sonotrode surface 


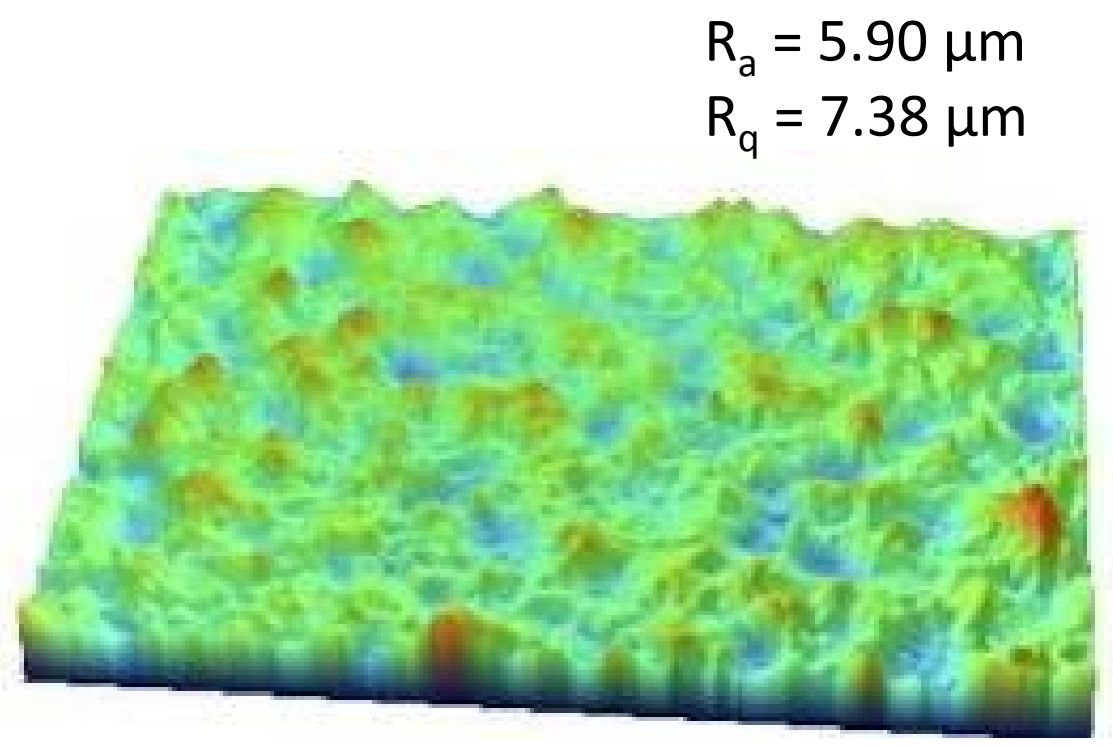

Figure 7 - Three dimensional optical profile of the EDM sonotrode surface 


$$
\begin{aligned}
& \mathrm{R}_{\mathrm{a}}=6.87 \mu \mathrm{m} \\
& \mathrm{R}_{\mathrm{q}}=8.71 \mu \mathrm{m}
\end{aligned}
$$

(a)

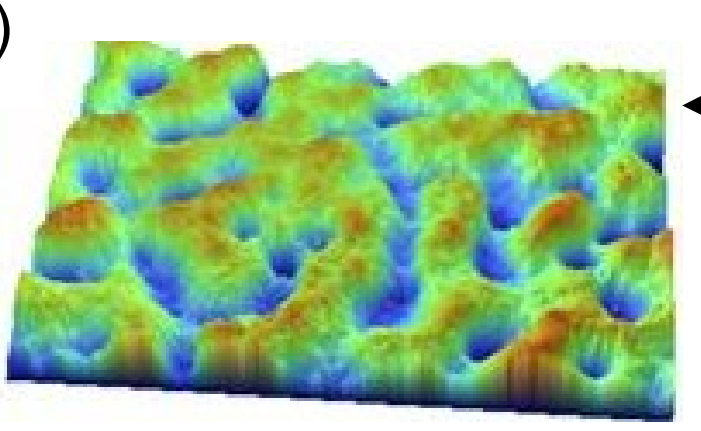

Sonotrode Texture

$\leftarrow$ via LE

Residual LE Foil Texture

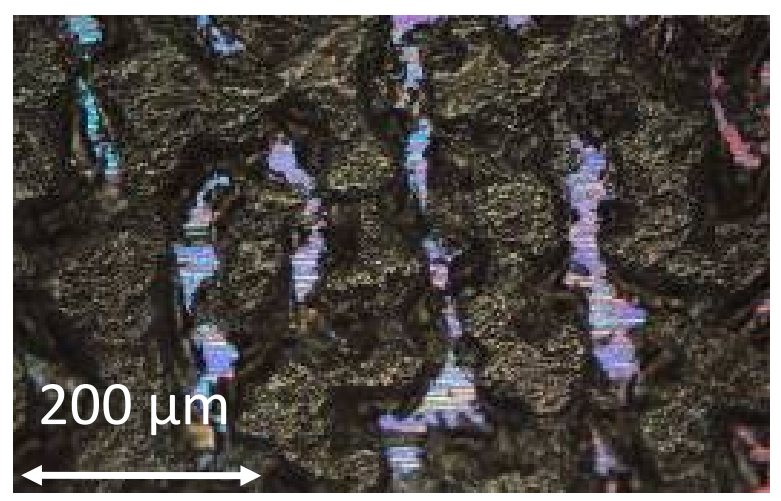

$$
\text { Pre-UC Foil: } \begin{aligned}
& R_{a}=0.09 \mu \mathrm{m} \\
& R_{q}=0.11 \mu \mathrm{m}
\end{aligned}
$$

$$
\begin{aligned}
& R_{a}=3.25 \mu \mathrm{m} \\
& R_{q}=4.13 \mu \mathrm{m}
\end{aligned}
$$

(b)

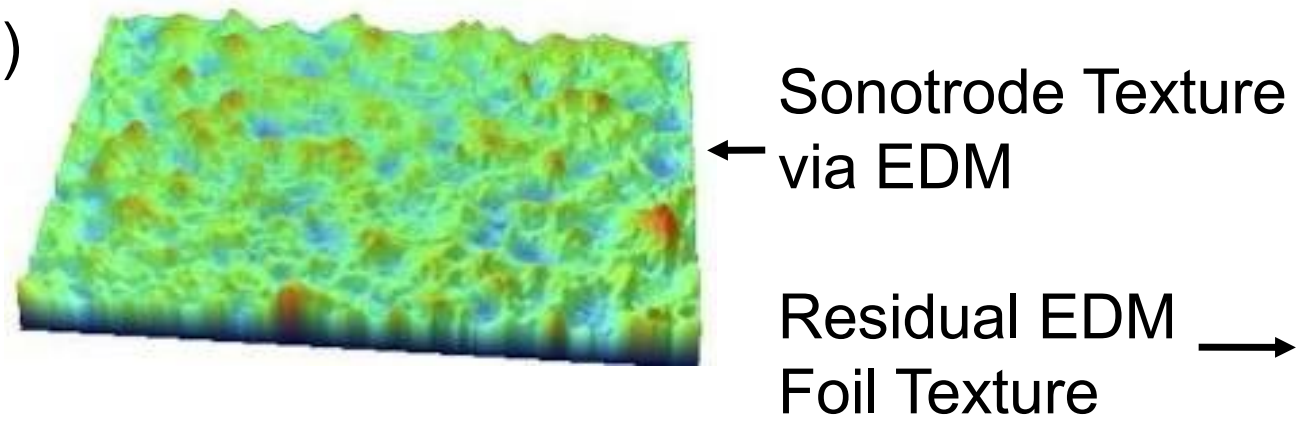

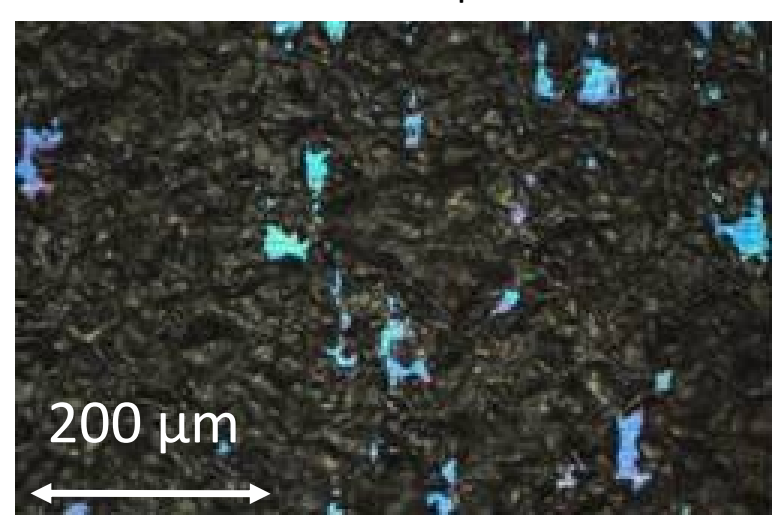

Figure 8 - LE (a) and EDM (b) sonotrode textures and the optical micrographs of the residual topologies left behind. The light areas are an indication of void volume/unprocessed foil material 
(a)

\section{$200 \mu \mathrm{m}$}

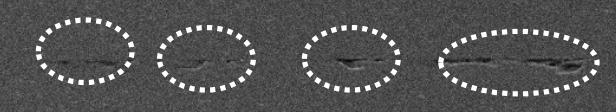

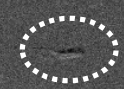
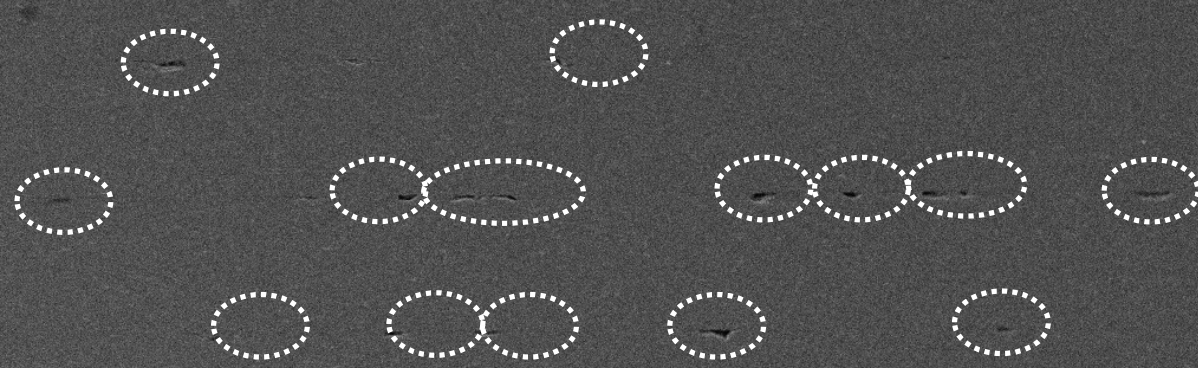

i.

(b)

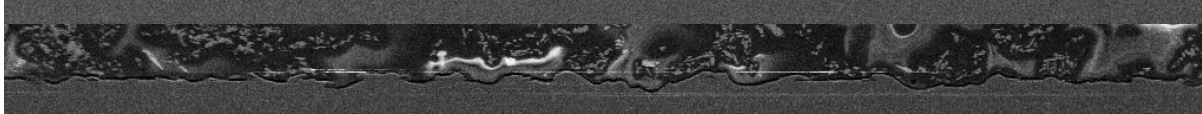

$200 \mu \mathrm{m}$
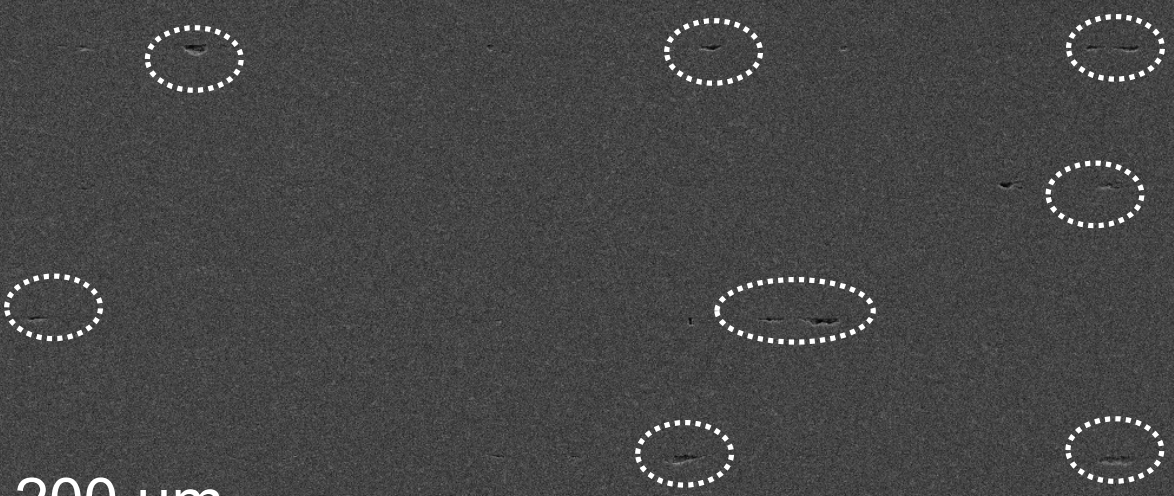

Figure 9 - (a) Cross section of top of a five layer stack of foil produced from LE textured sonotrode; (b) Cross section of a five layer stack produced from EDM textured sonotrode 


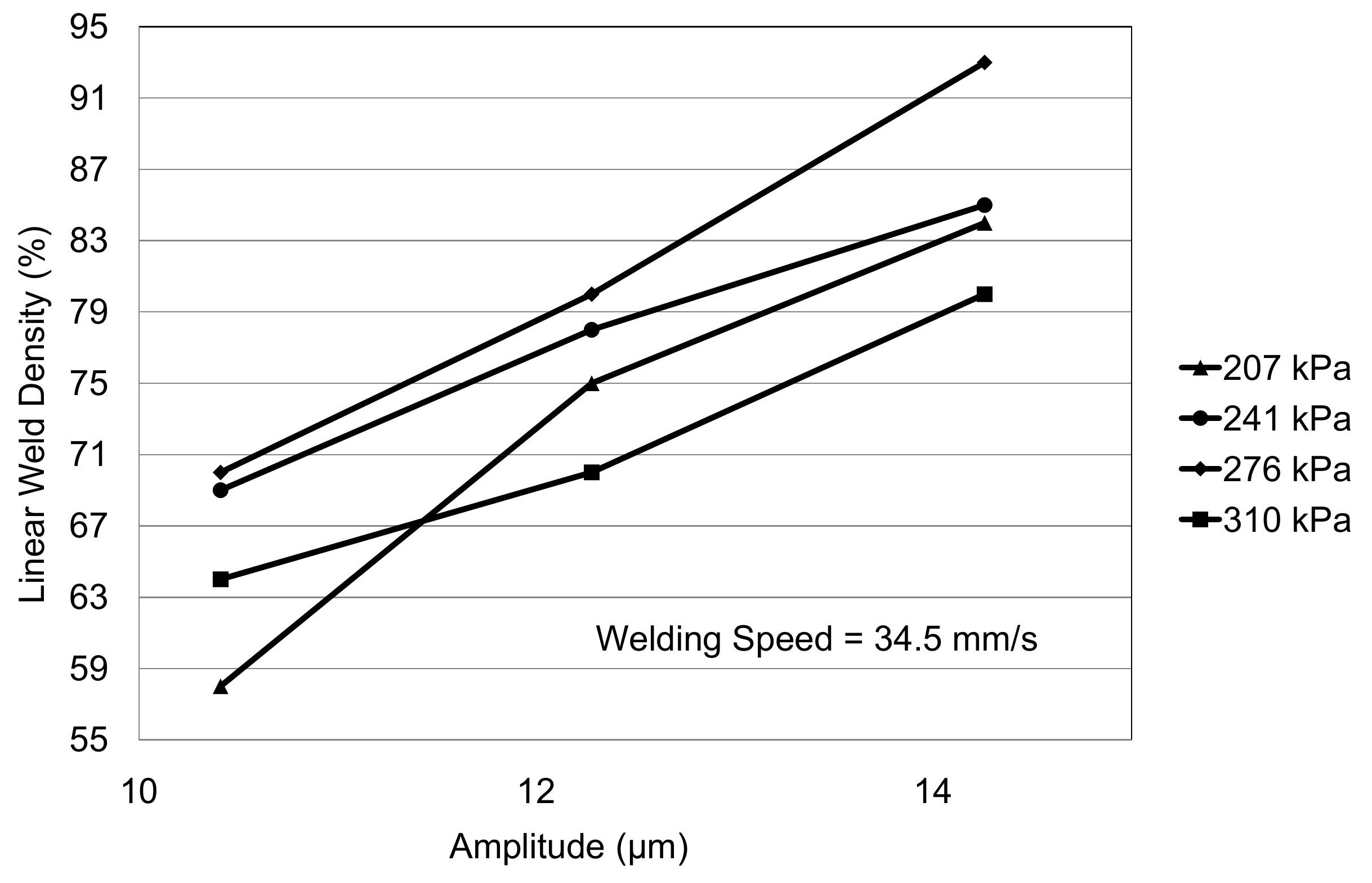

Figure 10 - A graph showing the average LWD results for UC Al 30030 


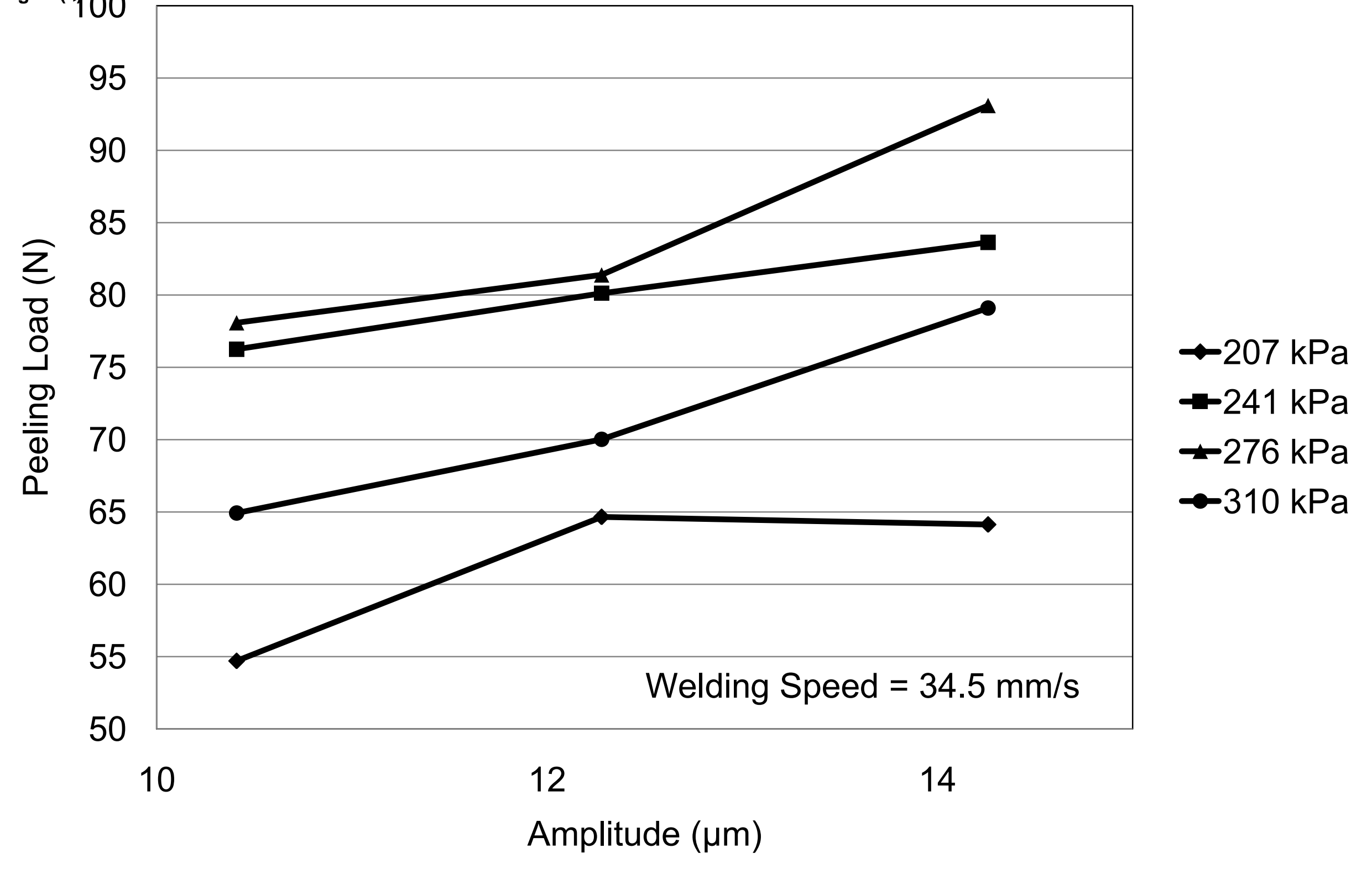

Figure 11 - A graph showing the average maximum peel load for UC Al 30030 
—Ductile failure mode -Brittle failure mode

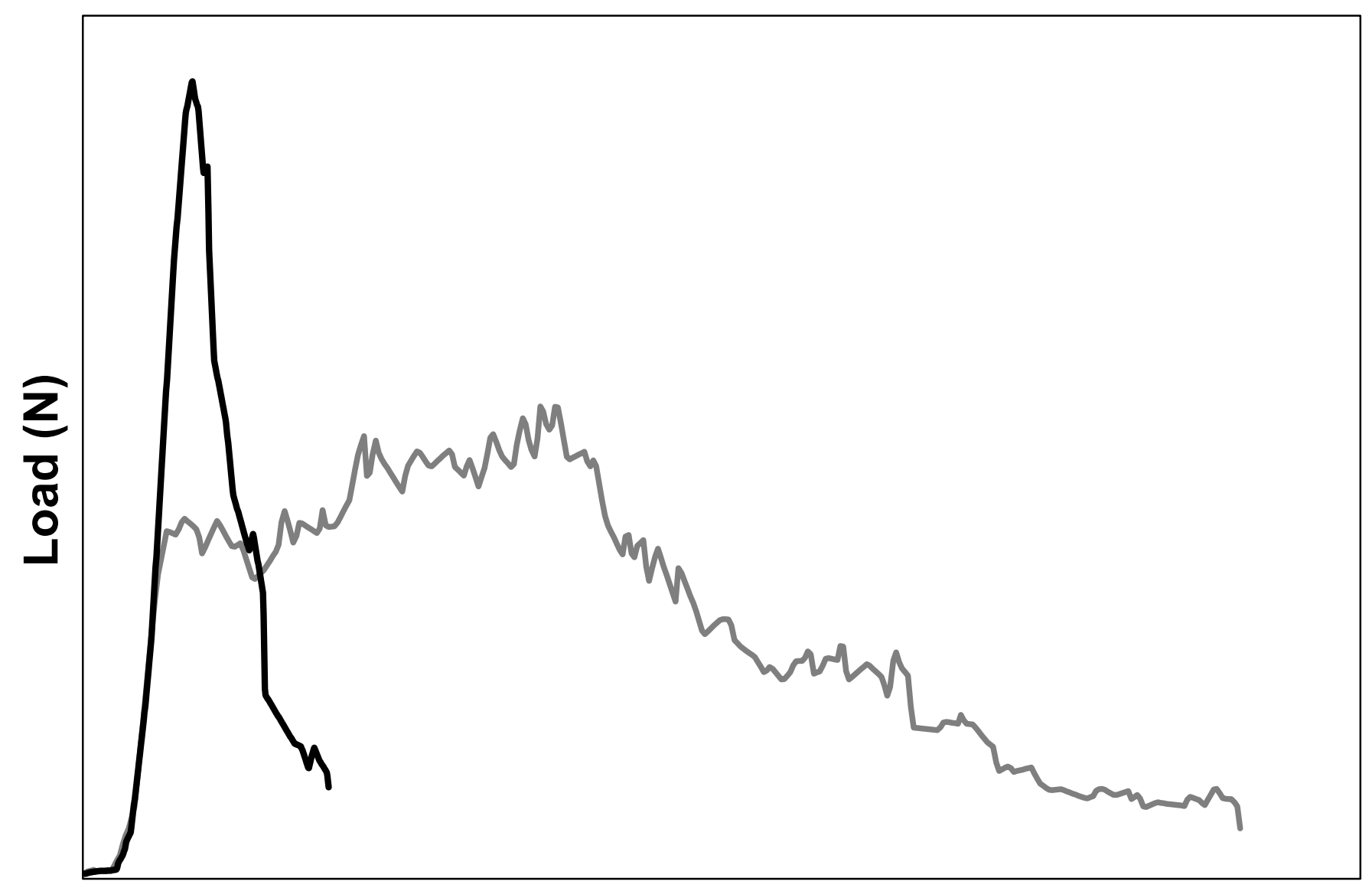

Extension ( $\mathrm{mm})$

Figure 12 - The peeling load vs. extension graph showing the two different forms of failure mode 


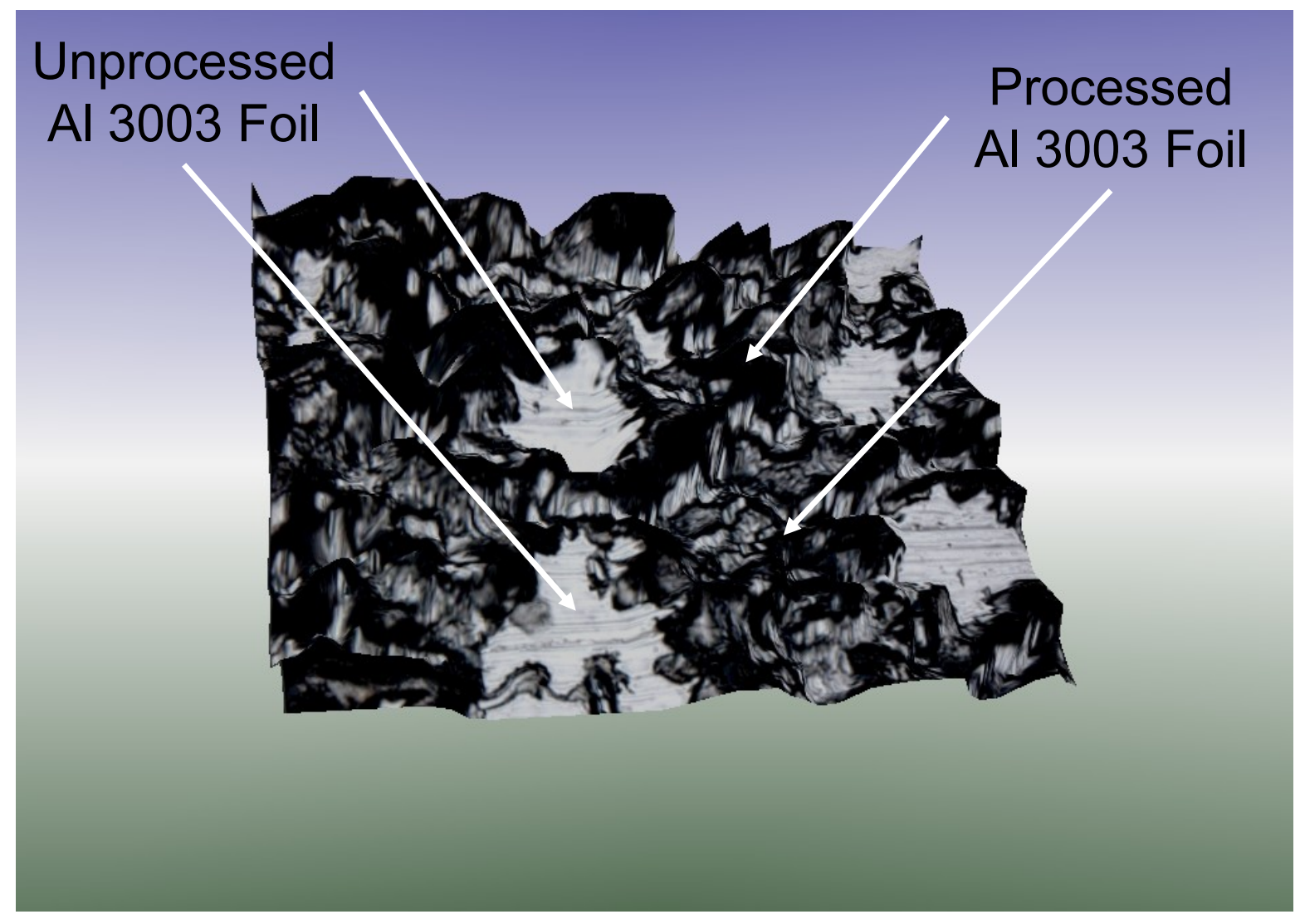

Figure 14 - A three dimensional optical micrograph of an Al 30030 interlaminar Ultrasonically Consolidated surface showing processed and unprocessed foil regions 
Figrig(s)e of Failure: Mechanical Peel Testing

a)

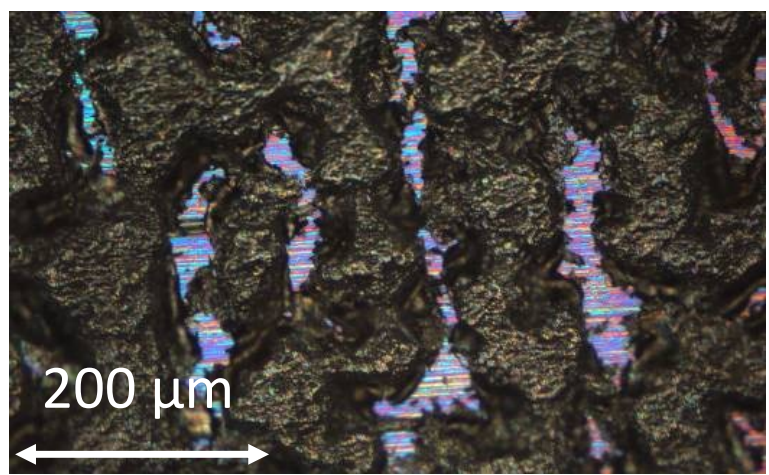

b)

$\mathrm{R}_{\mathrm{a}}=6.87 \mu \mathrm{m}$

$\mathrm{R}_{\mathrm{q}}=8.71 \mu \mathrm{m}$

c)

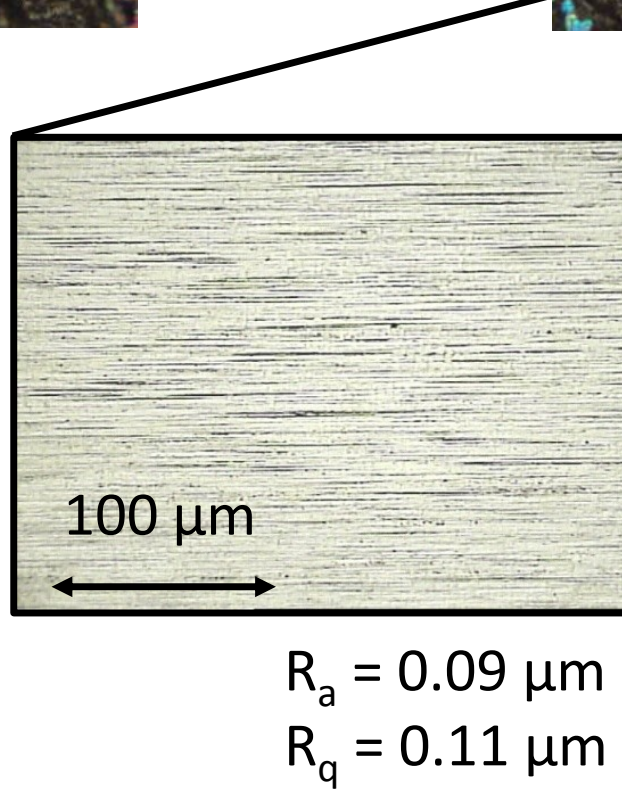

Figure 15 - Optical micrographs of the sonotrode texture imprint onto top foil (a), the residual texture (b) on bottom of tape (after subsequent layer bonding and forced separation via mechanical peel testing) and the void area - that remains in the as-rolled state (c) 


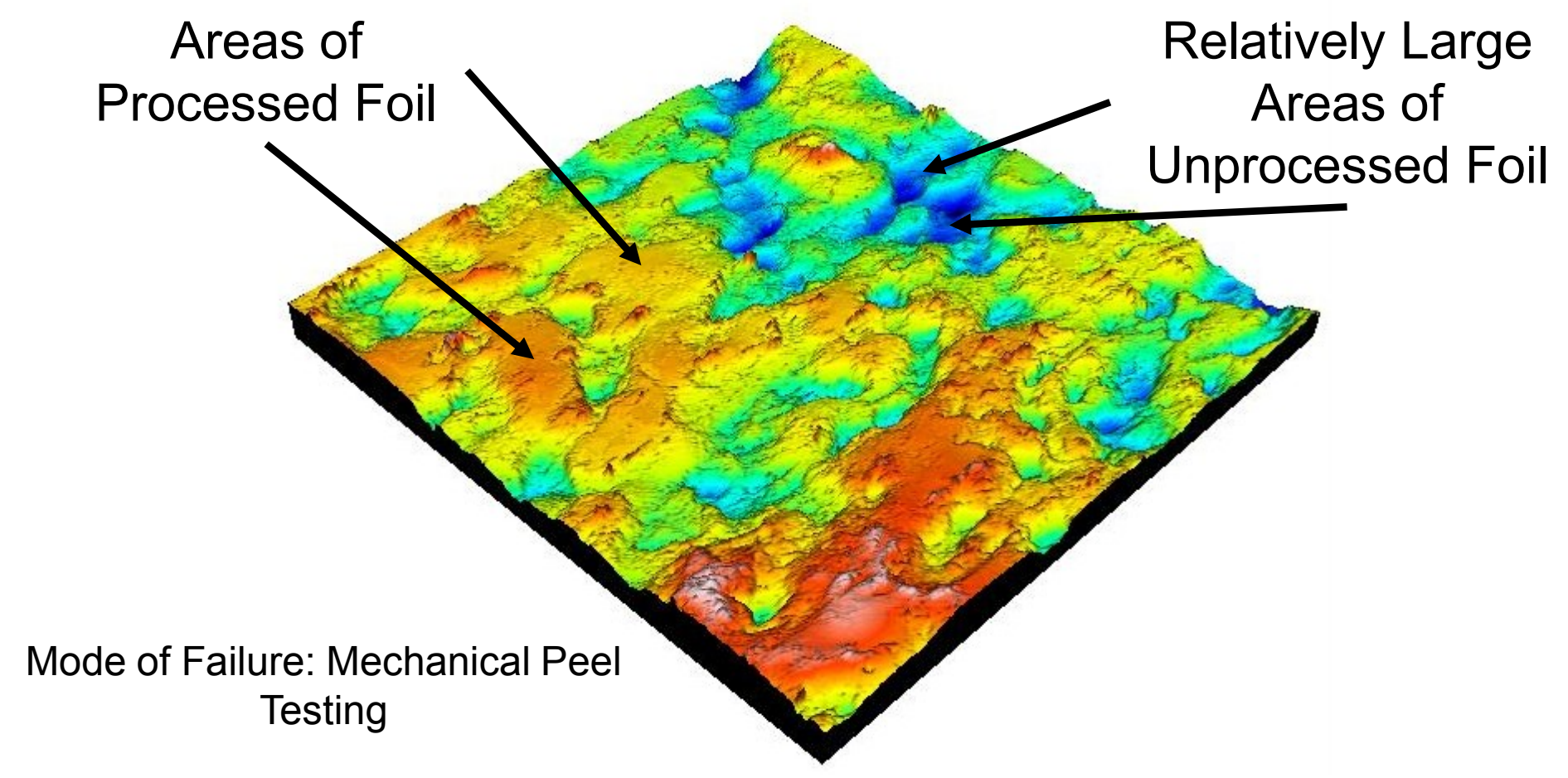

Figure 16 - Three dimensional optical profile of the interlaminar region for an Al 30030 sample produced via the parameters: $10.41 \mu \mathrm{m}, 1040 \mathrm{~N} 34.5 \mathrm{~mm} / \mathrm{s}$ 


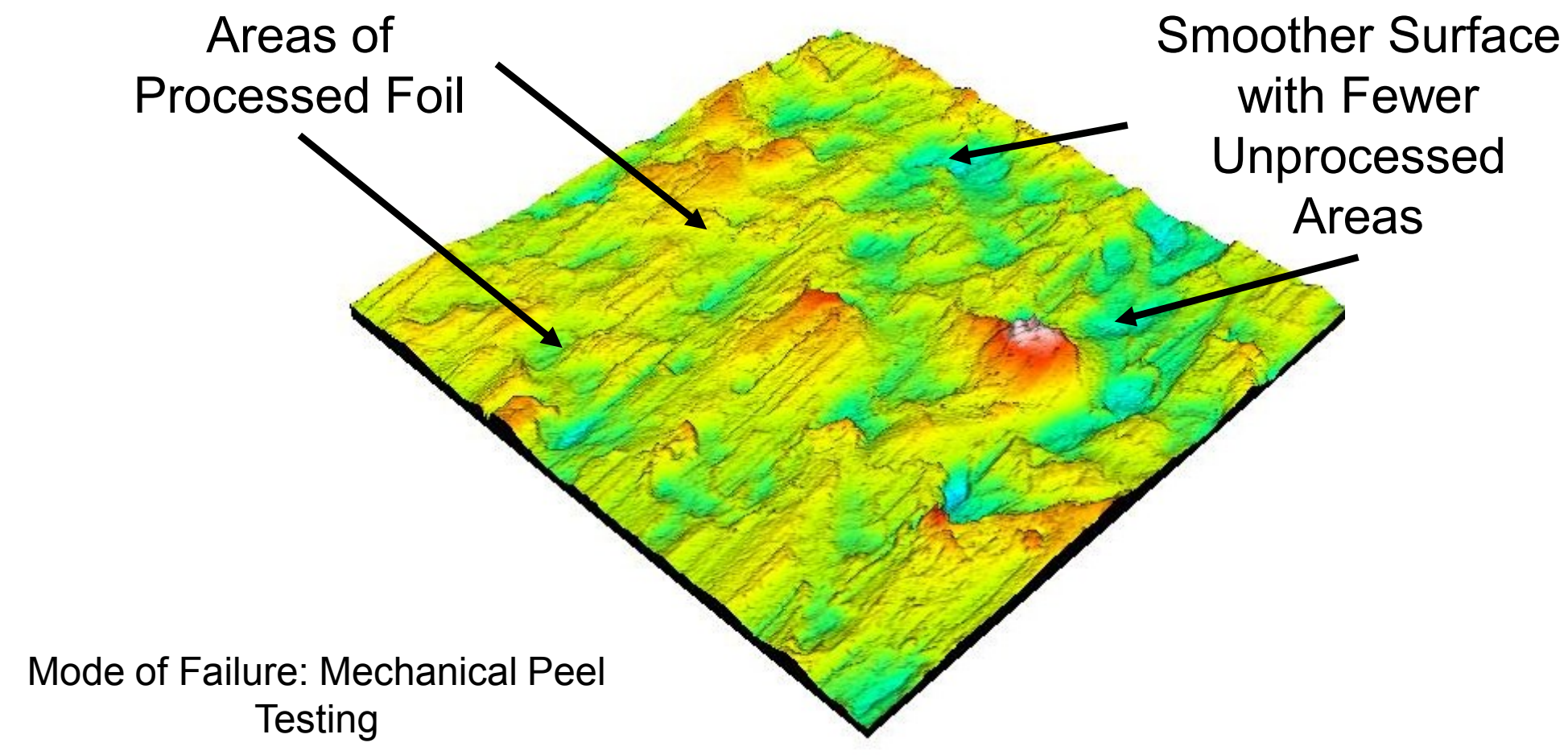

Figure 17 - Three dimensional optical profile of the interlaminar region for an Al 30030 sample produced via the parameters: $14.26 \mu \mathrm{m}, 1190 \mathrm{~N} 34.5 \mathrm{~mm} / \mathrm{s}$ 


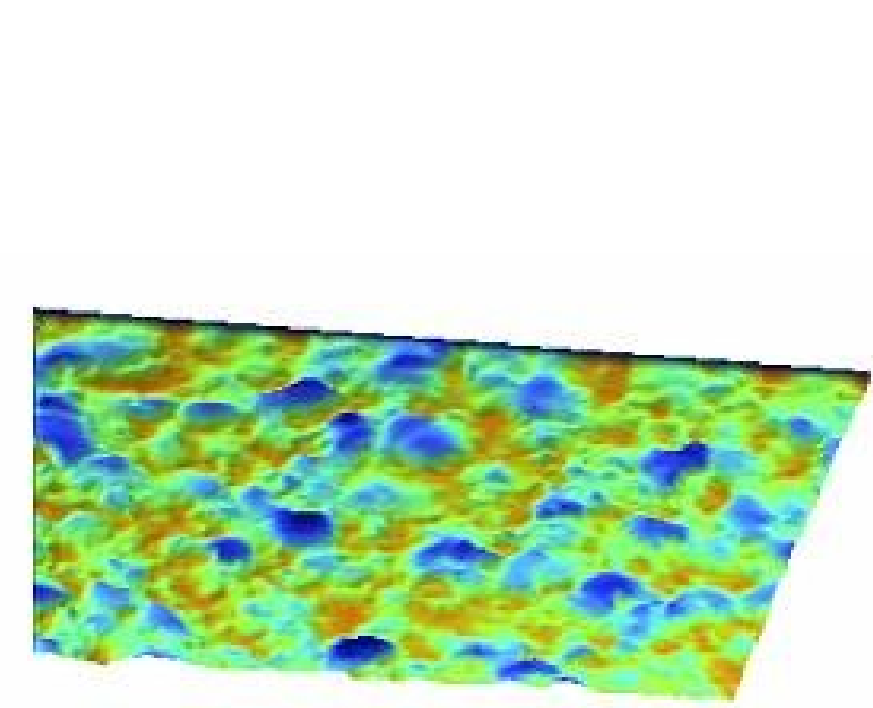

SonotrodeTexture

Al: Largely Plastic Deformation

Ti: Largely Elastic Deformation

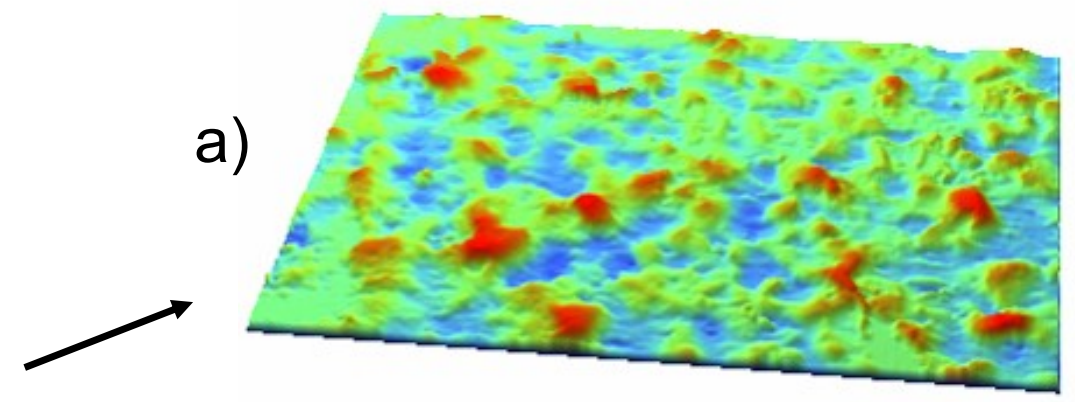

Al $3003 \mathrm{H}-18$ after UC

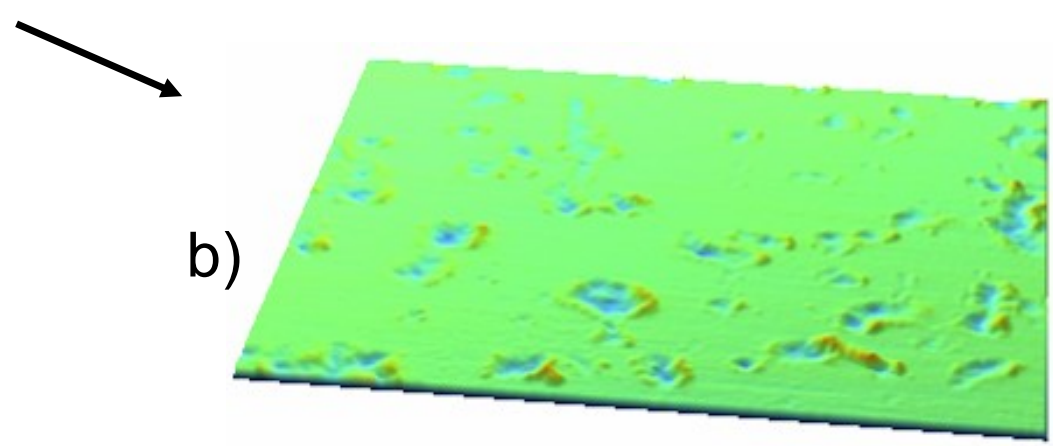

Commercially Pure

Ti after UC

Figure 18 - Three dimensional optical profile of the residual topology on deposited foil following the imprint of the sonotrode topology to (a) aluminium $3003 \mathrm{H}-18$ foil and (b) commercially pure titanium foil 


\begin{tabular}{|c|c|c|}
\hline Material Property & Al 3003-0 & Al $3003-$ H18 \\
\hline Density $\left(\mathrm{g} / \mathrm{cm}^{3}\right)$ & \multicolumn{2}{|c|}{2.73} \\
\hline UTS (MPa) & 110 & 200 \\
\hline Tensile Yield Strength (MPa) & 41.4 & 186 \\
\hline Elongation at Break (\%) & 30 & 10.0 \\
\hline Modulus of Elasticity (GPa) & \multicolumn{2}{|c|}{68.9} \\
\hline Poisson's Ratio & \multicolumn{2}{|c|}{0.33} \\
\hline Shear Modulus (GPa) & \multicolumn{2}{|c|}{25} \\
\hline Melting Temperature $\left({ }^{\circ} \mathrm{C}\right)$ & \multicolumn{2}{|c|}{$643-654$} \\
\hline Composition (\%) & \multicolumn{2}{|c|}{$\begin{array}{c}\mathrm{Al}(96.7 \text { - 99), Mn }(1-1.5), \mathrm{Cu}(0.05-0.2), \mathrm{Fe}(\leq 0.7), \mathrm{Si} \\
(\leq 0.6), \mathrm{Zn}(\leq 0.1), \text { Other }(\leq 0.15)\end{array}$} \\
\hline
\end{tabular}

Table 1 - Mechanical properties and composition of Al 3003 


\begin{tabular}{|c|c|}
\hline Measurement Attribute & Nominal Value \\
\hline Magnification & $5.1 X$ \\
\hline Measurement Array Size & $640 \times 480$ \\
\hline Lateral Sampling & $1.94 \mu \mathrm{m}$ \\
\hline Field of View & $1.20 \mathrm{~mm} \times 0.93 \mathrm{~mm}$ \\
\hline Height Resolution & $<6 \mathrm{~nm}$ \\
\hline Terms Removed & Tilt/cylinder only \\
\hline 3D filter & - Gaussian $-125 \mathrm{~mm}^{-1}$ \\
\hline Stylus X lc/ls & $1 \mathrm{~mm} / 10 \mu \mathrm{m}$ \\
\hline Stylus Y lc/ls & $0.8 \mathrm{~mm} / 8 \mu \mathrm{m}$ \\
\hline Stylus Filter Type & Gaussian \\
\hline
\end{tabular}

Table 2 - WYKO NT 8000 system parameter settings 


\begin{tabular}{|c|c|c|c|}
\hline & $\begin{array}{c}\text { Weld } \\
\text { Force (N) }\end{array}$ & $\begin{array}{c}\text { Sonotrode } \\
\text { Amplitude }(\boldsymbol{\mu m})\end{array}$ & $\begin{array}{c}\text { Welding Speed } \\
(\mathbf{m m} / \mathbf{s})\end{array}$ \\
\hline Weld & 1400 & 19 & 42.3 \\
\hline Tack & 300 & 16 & 42.3 \\
\hline
\end{tabular}

Table 3 - UC weld parameters (at $149^{\circ} \mathrm{C}$ ) for laminate samples used to determine sonotrode texture transfer 


\begin{tabular}{|c|c|c|}
\hline Welding Speed $(\mathrm{mm} / \mathrm{s})$ & Sonotrode Amplitude ( $\mu \mathrm{m})$ & Weld Force (N) \\
\hline \multirow{12}{*}{34.5} & \multirow{4}{*}{10.41} & 895 \\
\hline & & 1040 \\
\hline & & 1190 \\
\hline & & 1335 \\
\hline & \multirow{4}{*}{12.28} & 895 \\
\hline & & 1040 \\
\hline & & 1190 \\
\hline & & 1335 \\
\hline & \multirow{4}{*}{14.26} & 895 \\
\hline & & 1040 \\
\hline & & 1190 \\
\hline & & 1335 \\
\hline
\end{tabular}

Table 4 - The combinations of processing parameters used to produce the ultrasonically consolidated peel testing samples 


\begin{tabular}{|c|c|}
\hline Measurement Variable & Variable Setting \\
\hline Objective Lens & Mirau $\times 10$ \\
\hline Measurement Array Size & $640 \times 480$ at $30 \mathrm{~Hz}$ \\
\hline Manual Image Zoom & $\times 2$ magnification \\
\hline Field of View & $\mathrm{X}: 0.35 \mathrm{~mm} \mathrm{Y:} 0.26 \mathrm{~mm}$ \\
\hline Height Resolution & $\leq 0.1 \mathrm{~nm}$ \\
\hline Frequency Domain Analysis (FDA) Resolution & High \\
\hline Scan Length & $100 \mu \mathrm{m}$ bipolar \\
\hline Mid Mod & $1 \%$ \\
\hline Stitch Image Number & $9=3$ columns $\times 3$ rows \\
\hline Stitch Image Overlap & $25 \%$ \\
\hline Stitched Image Size & $\mathrm{X}: 0.87 \mathrm{~mm} \mathrm{Y:} 0.66 \mathrm{~mm}$ \\
\hline
\end{tabular}

Table 5 - Zygo NewView 5000 system parameter settings 


\begin{tabular}{|c|c|c|c|}
\hline & LE & EDM & Pre-UC Foil \\
\hline $\begin{array}{c}\mathbf{R}_{\mathbf{a}} \\
(\boldsymbol{\mu \mathbf { m }})\end{array}$ & 12.94 & 5.90 & 0.09 \\
\hline $\begin{array}{c}\mathbf{R}_{\mathbf{q}} \\
(\boldsymbol{\mu \mathbf { m }})\end{array}$ & 15.93 & 7.38 & 0.11 \\
\hline
\end{tabular}

Table $6-\mathrm{R}_{\mathrm{a}}$ and $\mathrm{R}_{\mathrm{q}}$ values for the sonotrode with LE surface, the sonotrode with EDM surface and the Pre-UC Foil 


\begin{tabular}{|c|c|c|}
\hline Sonotrode Amplitude ( $\mu \mathrm{m})$ & Weld Force $(\mathbf{N})$ & Average $3 D R_{a}(\mu \mathrm{m})$ \\
\hline \multirow{4}{*}{10.41} & 895 & 5.03 \\
\hline & 1040 & 4.81 \\
\hline & 1190 & 4.76 \\
\hline & 1335 & 5.44 \\
\hline \multirow{4}{*}{12.28} & 895 & 4.88 \\
\hline & 1040 & 4.22 \\
\hline & 1190 & 4.28 \\
\hline & 1335 & 5.25 \\
\hline \multirow{4}{*}{14.26} & 895 & 4.85 \\
\hline & 1040 & 4.13 \\
\hline & 1190 & 4.14 \\
\hline & 1335 & 5.20 \\
\hline
\end{tabular}

Table 7 - Average Al 3003-0 interlaminar $\mathrm{R}_{\mathrm{a}}$ measurements for various UC process parameters at $34.5 \mathrm{~mm} / \mathrm{s}$ welding speed 